NIST

PUBLICATIONS

\section{Visibility of Exit Directional Indicators}

\section{Belinda L. Collins Peter J. Goodin}

\author{
U.S. DEPARTMENT OF COMMERCE \\ Natlonal Instltute of Standards \\ and Technology \\ Bullding and Fire Research Laboratory \\ Galthersburg, MD 20899 \\ Sponsored by \\ Natlonal Electrlcal Manufacturers \\ Assoclation \\ Washington, DC 20037
}

U.S. DEPARTMENT OF COMMERCE Robert A. Mosbacher, Secretary NATIONAL INSTITUTE OF STANDARDS AND TECHNOLOGY

John W. Lyons, Director

$Q C$

100

.456

\#4532

1991

C. 2 



\section{Visibility of Exit Directional Indicators}

\section{Belinda L. Collins Peter J. Goodin}

U.S. DEPARTMENT OF COMMERCE National Institute of Standards and Tochnology Bullding and Fre Research Laboratory Galthersburg, MD 20899

Sponsored by

Natlonal Electrlcal Manufacturers Assoclation

WashIngton, DC 20037

March 1991

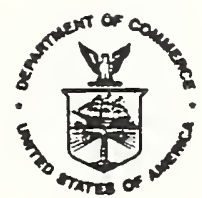

U.S. DEPARTMENT OF COMMERCE Robert A. Mosbacher, Secretary NATIONAL INSTITUTE OF STANDARDS AND TECHNOLOGY John W. Lyons, DIrector 

A three-phase experiment assessed the effectiveness of different configurations for exit signs and directional indicators. Two phases involved visibility assessments, while a third phase was a behavioral assessment. In the experiment, sign effectiveness was determined in terms of distance to detection, correct identification, and rated effectiveness, as well as speed through a corridor. The results indicated that a chevron in grey on white with a contrast of about 0.4 to 0.5 (to meet minimum specifications) was identified correctly at the greatest mean distance and received the highest mean ratings of effectiveness, as compared to other directional indicators. The combination of a 2.25 -in chevron with a 6-in EXIT sign was identified correctly at a mean distance of about $100 \mathrm{ft}$. Use of color, either red or green, increased this distance by about 15 to $20 \mathrm{ft}$. Reducing width to height ratio reduced identification distance by about 35-40 ft for chevrons of comparable height, although chevrons of 2.6 to 3.75 -in. in height, with a width to height ratio of 0.29 to 0.43 , were identified correctly at about $100 \mathrm{ft}$. These data suggest that chevron width could be reduced if height were increased above 2.6-in, and still maintain adequate visibility at $100 \mathrm{ft}$. However, visibility is best predicted by total chevron area, with chevrons with larger total areas seen at greater distances. Analysis of the movement data from the behavioral phase indicated that chevrons of 2.25 -in provided adequate visibility at about $100 \mathrm{ft}$ but that speed of movement is not a sensitive indicator for sign visibility. Finally, the data from all three phases indicate the importance of chevron size and configuration as well as sign color and contrast in determining visibility.

\section{Keywords:}

Arrows, chevrons, color, contrast, directional indicators, exit, egress, emergency lighting, sign, visibility. 


\section{FOREWORD}

This report summarizes research conducted from November 1989 to August 1990, under contract with the National Electrical Manufacturers Association.

\section{ACKNOWLEDGEMENTS}

The authors wish to acknowledge the invaluable assistance of Mr. Charles Bulik, who designed and implemented the instrumentation for the second phase, Ms. Anna Dato, who entered the data for the first phase, Mr. Rocky Somers who entered the data for the second and third phases, Ms. Jennifer Wright who assisted in the data collection for both phases 2 and 3, Ms. Dorothy Garland of the NIST Safety Office who coordinated observers for phase 2, Mr. Stefan Leigh who assisted with the statistical analysis, all the observers who participated, and members of the National Electrical Manufacturers Association (NEMA) for their technical advice and support.

\section{DISCLAIMER}

Any commercial products or trade names mentioned in this report are included for informational purposes only, and do not constitute and endorsement or recommendation by the National Institute of Standards and Technology or the National Electrical Manufacturers Association. 
Table of Contents

Abstract $\ldots \ldots \ldots \ldots \ldots \ldots \ldots \ldots \ldots \ldots \ldots \ldots \ldots \ldots \ldots$ iii

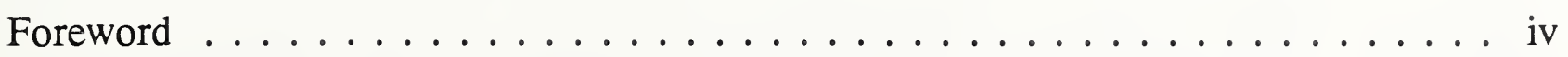

List of Figures $\ldots \ldots \ldots \ldots \ldots \ldots \ldots \ldots \ldots \ldots \ldots \ldots \ldots \ldots \ldots \ldots$

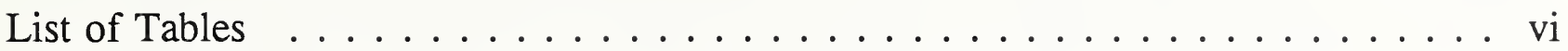

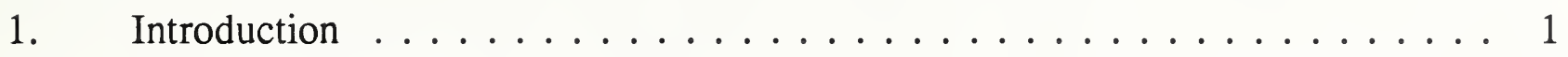

$1.1 \quad$ Background . . . . . . . . . . . . . . . . 1

2. Phase 1 - Initial Visibility Assessment $\ldots \ldots \ldots \ldots \ldots \ldots \ldots$

2.1 Phase 1 Procedure . . . . . . . . . . . . . . . . 2

2.2 Results for Phase $1 \ldots \ldots \ldots \ldots \ldots$

3. Phase 2 - Behavioral Assessment . . . . . . . . . . . . . 13

3.1 Procedure for Phase $2 \ldots \ldots \ldots \ldots \ldots$

3.2 Results for the Behavioral Assessment . . . . . . . . . . . . . 14

4. Phase 3 - Follow-up Visibility Assessment . . . . . . . . . . . . 20

4.1 Procedure for Phase $3 \ldots \ldots \ldots \ldots$

4.2 Results for Phase $3 \ldots \ldots \ldots \ldots$

5. Discussion and Conclusions $\ldots \ldots \ldots \ldots \ldots \ldots \ldots$

6. References .......................... . . . 27

Appendix A. Comments Made by Subjects During Behavioral Evaluation . . . . . 28 


\section{List of Figures}

Figure 1. Boxplots of data for exit directional indicators from phase $1 \ldots \ldots 6$ Figure 2. Boxplots of data for Exit words combined with chevrons from phase

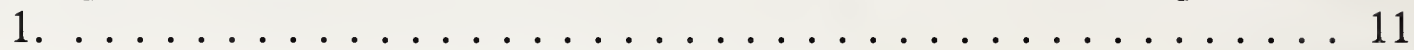

Figure 3. Boxplot of data for the behavioral assessment. . . . . . . . . . 17

Figure 4. Boxplots of identification distance and ratings as a function of chevron height for the data from ............... 22

Figure 5. Mean identification distance as function of chevron width for chevrons in phase three, and as a function of area for red and green signs from phase 3 , and grey signs from both phases 1 and $3 . \ldots 24$

List of Tables

Table 1. Data on Detection, Identification and Rating Distance for Directional

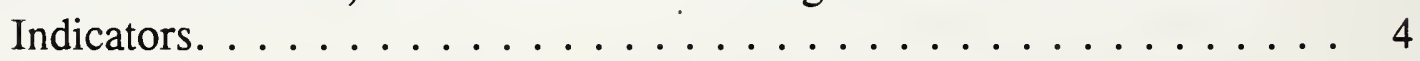

Table 2. Summary Data for the Combination of Words and Chevrons . . . . . 8 Table 3. Mean Identification Distance, Rating and Speed for Behavioral Phase . . . . . . . . . . . . . . . . . . 16

Table 4. Percentage of Spontaneous Comments Made During Behavioral Assessment . . . . . . . . . . . . . . . . . . . 19

Table $5 . \quad$ Visibility Data for Phase $3 \ldots \ldots \ldots \ldots \ldots \ldots \ldots$ 


\section{Introduction}

\subsection{Background}

The purpose of the present research was to determine the size at which different directional indicators, such as arrows, are visible for an exit sign at a specified distance. The National Fire Protection Association is currently revising the Life Safety Code (NFPA 101) to standardize the inclusion of a directional indicator (i.e., "arrow") with the word "EXIT". The current version of NFPA 101 (1988) specifies the use of an arrow located outside the exit legend "of such size, character and location that it is plainly visible and identifiable as a directional indicator". This wording allows arrows of any shape and size to be located below, above, and to the side of the legend - provisions which are not very specific. A proposed revision suggests the use of a 2.25 -in ${ }^{1}$ chevron (an arrow-type shape with no tail as shown in table 1) located to the left and/or right of the 6-in exit legend. Yet, it is not known whether the chevron is the best shape or whether 2.25-in is the best size for adequate visibility at $100 \mathrm{ft}$. - the maximum distance required by NFPA for locating exit signs from a means of egress. Furthermore, it is also not known whether the arrow needs to be visible at 100 -ft., or at what distance an arrow is visible enough to ensure proper directional movement.

The present study is an extension of findings from previous work by Lerner (1981), Collins and Lerner (1983), Underwriters Laboratory (UL) (1988), and Young $(1988,1989)$ which indicated that the most visible and effective directional indicator is a chevron. The present study assessed the detectability of several arrow shapes, including a chevron, and determined their effectiveness in indicating direction. It concentrated, however, on determining the best configuration for the combination of a chevron with the exit legend. Thus, it was intended to confirm previous results about the effectiveness of chevrons as directional indicators, and determine the best size and location for combination with the word "EXIT" in terms of both visibility and egress behavior.

A three-phase study was performed. In the first, the visibility of different directional indicators and chevron sizes was assessed as a function of distance. In the second, the effectiveness of chevrons of different sizes and colors combined with the word "EXIT" in guiding people through a corridor was explored. In the third, the effectiveness of chevrons of different widths, colors, and sizes (again with the word exit) was evaluated as a function of distance.

\section{Phase 1 - Initial Visibility Assessment}

Phase 1 was intended to: 1 ) determine the distance at which directional symbols are visible

1 IPS units are used in the text for Exit sign and distance specification since both NFPA and UL use these as their primary units. 
and effective as directional indicators; and 2) evaluate the best size and location for directional indicators relative to a six-in word legend. In phase 1 , the distance at which five different arrow shapes could be detected and identified was determined for 20 observers. In addition, the visibility of six different sizes of chevron combined with a 6-in word "EXIT" was also determined for the same 20 observers.

\subsection{Phase 1 Procedure}

A windowless tunnel at NIST with $50 \mathrm{~m}(164 \mathrm{ft})$ of unobstructed travel space was used for phase 1 . An illuminance of 1 to $2 \mathrm{~lx}$ was provided on the floor by incandescent bulbs located at the upper right side of the tunnel to simulate emergency lighting conditions (NFPA, 1988). The tunnel's walls were light to medium grey concrete and marked at $2 \mathrm{ft}$ intervals for distance determination. The floor of the tunnel was lit to 1 to $2 \mathrm{~lx}$, while the wall nearest the observer's eyes was lit to about $5 \mathrm{~lx}$. The exit sign itself was located 50 $\mathrm{m}(164 \mathrm{ft})$ from the observer. The sign was externally illuminated with $54 \mathrm{~lx}(5 \mathrm{fc})$ of tungsten illumination as suggested by NFPA 101 (1988). Observers adapted to the prevailing luminance for about $5 \mathrm{~min}$ before the experiment began.

A total of 42 arrows, words, and a combination of both were used in phase 1 . Twelve symbols (ten arrows, one EXIT, and one NO SMOKING symbol) were evaluated to determine the distance at which they could be detected (seen) and identified. Two directions (left and right) were used with five unique arrow shapes for a total of ten arrow signs. For the combination of word and directional signs, the word "EXIT" or a look-alike word "FKIT" was used to ensure that the observer read the sign and did not simply assume that any word was "EXIT". These words were combined with a chevron in one of six different sizes and four locations for a total of 28 word-directional indicator combinations. Thus, the chevron could face left or right and be located to the left or right of the word. Finally, the words EXIT and FKIT were assessed alone.

All 42 signs were reproduced at a contrast of 0.45 using grey lettering on a white background to approximate the NFPA recommended minimum for an exit sign. The set-up used to measure luminance, from which contrast was calculated, was that suggested in UL 924 (1989). The external source was located $5 \mathrm{ft}$ from the sign with the photometer placed to one side, to minimize specular reflections. The grey signs were printed on matte paper, (although the red and green signs used in phases 2 and 3 were more somewhat specular). Five to sixteen luminance measures were taken for each character and averaged to calculate contrast with the background. The directional reflecting characteristics of the stroke and background were not measured. All word signs were 6-in. in height, while the symbol signs were 2.5 -in. in height. When directional symbols were combined with a word legend, they ranged in size from 0.75 -in to 4.25 -in. Chevron direction varied randomly from left to right. Consistency was also varied with half the signs being consistent, half inconsistent. Consistency was defined as agreement between the position of and direction indicated by the chevron; e.g., a chevron located to the left of the word and pointing left was "consistent"; one pointing right was "inconsistent". 
A total of 20 observers, 12 males and 8 females, all NIST employees or visitors, ranging in age from 20 to 50 were used in the initial visibility assessment. Fifteen percent were between 18 and $25 ; 35 \%$ were between 26 and 30; 20\% were between 31 and 39; and 30\% between 40 and 49 . About half of the observers required some visual correction. Although the observers were relatively young, at least two observers reported visual acuity of less than $20 / 20$. No observer reported any color deficiency. The total experimental time was about one and one-half hours but observers were advised that they could quit at any time if they became fatigued (although none did).

During phase 1, four dependent variables were assessed - distance to detection, identification, certain identification, and rated effectiveness - as a function of sign parameters including shape of directional indicator, word, chevron size, and chevron location. Detection distance represented the distance at which the observers first indicated that something was visible on the sign, although they could not necessarily say what "it" was. Identification distance was the distance at which the sign was first correctly identified, while confident identification occurred when the observers indicated they were sure of the identification. These definitions mean that detection should occur at a greater distance than identification, which in turn should be greater than certain identification distance. To obtain these data, observers (tested individually) walked forward from the starting point (164 ft from the sign) to the point at which they first detected something on the sign, where they stopped. Distance from this point to the sign was measured as an overall indicator of the detectability, not the readability, of the sign message. Observers then moved forward as necessary, stopped, identified the sign, and indicated the direction that they would turn, if any. The distance to the sign was again recorded as an indicator of the readability of the sign, and its ability to direct behavior. Observers then moved forward again, and indicated the distance at which they were sure that they could identify the sign (if they became more certain). Finally, they moved forward to a point $60 \mathrm{ft}(18.3 \mathrm{~m})$ from the sign where they rated the effectiveness of the sign on a 7-point scale. On this scale, a "1" meant "Not at all Effective", while a "7" meant "Very Effective". This measure was an indicator of the effectiveness (defined as the ability to see, recognize, read, and follow) of the individual sign to the observer. In some instances, observers had to walk beyond the rating point to identify the sign because the chevron was too small to be identified at this distance. In these cases, they returned to the rating point to make their ratings. This procedure was repeated 42 times for each observer. Each of the 42 signs was presented to the observers in random order so that they would not be able to anticipate an individual sign but would pay maximum attention to each sign. Thus, on any given trial an observer might see a directional symbol, a word plus directional symbol, a non-directional symbol, or a word alone. The same procedure was followed for each sign, even though several signs did not indicate a direction.

\subsection{Results for Phase 1}

Table 1 presents summary data on the visibility of exit directional indicators in terms of means and standard deviations of the distance to detection, identification, and certain 
Table 1. Data on Detection, Identification and Rating Distance for Directional Indicators.

All arrows are 2.5-in, while all distances are in feet.

Sign Description

1 Left Arrowhead With Tail

2 Left Chevron

3 Left Triangle

4 Left DOT Arrow
With Tail

5 Left Arrow

(Angelfish)

6 Right Arrow

With Tail

7 Right Chevron

8 Right Triangle

9 Right DOT Arrow With tail

10 Right Arrow

(Angelfish)

11 EXIT Symbol

12 No Smoking Symbol
Detect

$\begin{array}{rr}\text { Avg } & 144.2 \\ \text { Std } & 24.0\end{array}$

Avg $\quad 130.1$

Std $\quad 21.5$

Avg $\quad 140.6$

Std 24.7

Avg $\quad 148.1$

Std $\quad 19.5$

Avg $\quad 118.4$

Std $\quad 32.2$

Avg $\quad 142.2$

Std 24.8

Avg $\quad 132.2$

Std 30.3

Avg $\quad 123.5$

Std $\quad 25.3$

Avg 144.4

Std 24.8

Avg 125.9

Std $\quad 30.1$

Avg $\quad 138.1$

Std

Avg $\quad 109.1$

Std
Identify

71.8

20.8

92.7

27.7

65.7

19.0

86.1

20.1

72.9

30.9

73.0

27.9

93.2

29.3

64.9

16.2

89.4

19.5

68.6

16.9

28.5

7.5

21.3

10.8
Confident

60.6

25.9

76.0

30.0

56.9

20.2

71.1

22.0

55.4

22.9

56.2

18.3

82.7

21.7

51.3

16.1

80.7

21.1

59.0

24.6

28.5

7.5

21.3

10.8
Rating Graphic

1.8

0.8

3.3

1.5

1.6

0.6

3.0

1.4

1.8

0.9

1.9

1.1

2.6

1.4

1.6

0.9

3.3

1.3

1.9

1.0

1.0

0.0

1.2

0.7
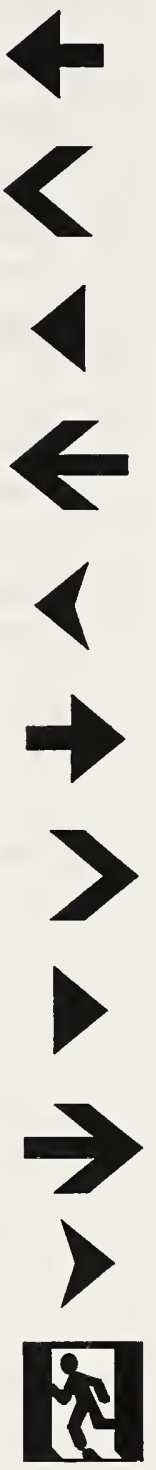

(9) 
identification. It also presents data on mean rated effectiveness using the seven-point scale described earlier.

Examination of the data in Table 1 for the directional indicators indicates that "something" was detected as visible on the sign between about 118 to $148 \mathrm{ft}$ depending on the indicator. Correct identification occurred at much shorter mean distances -- between 65 and $93 \mathrm{ft}$ from the sign. Confident identification occurred at shorter distances -- 55-83 ft from the sign.

Because the distance of primary interest for emergency egress is the distance at which a sign is first correctly identified, most of the analysis will focus on identification distance. Inspection of the data reveals clear differences between the types of directional indicators. The two chevrons were identified at the greatest mean distance $(92.7$ and $93.2 \mathrm{ft}$ for the left and right) while the DOT-AIGA arrows were identified at means of 86.1 and $89.4 \mathrm{ft}$ (left and right). The two triangles were identified at the shortest mean distances -- about $65 \mathrm{ft}$, while the arrowhead with tail and the "angel fish" were identified at mean distances between 68 and $73 \mathrm{ft}$. As might be expected, confident identification followed a similar pattern for the different indicators. These data thus indicate that a chevron by itself was visible at a mean distance of about $90 \mathrm{ft}$. Three observers identified the chevron at substantially shorter distances (about $50 \mathrm{ft}$ ), while three observers identified it at much longer distances (greater than $130 \mathrm{ft})$.

The pattern for rated effectiveness tended to follow that for identification distance. The least visible signs (the triangles) received the lowest mean ratings -- 1.6, while the most visible signs (the chevrons and DOT arrows) received the highest ratings (3.3 to 2.6). The data for the directional indicators (or arrows) may be compared with those for the two symbols -- EXIT and NO SMOKING. While these symbols were also 2.5-in. in height, they were much more complex visually. The result was a dramatic decrease in mean identification distance to between 21 and $28 \mathrm{ft}$ from the sign with the EXIT symbol being slightly more "visible" than the NO SMOKING symbol.

Figure 1 presents another way of summarizing the data for directional indicators. In the four plots shown in Figure 1, the data are presented as boxplots (McNeil, 1977) generated by Dataplot (Filliben, 1981). In these plots, the total range is represented by the top and bottom "whiskers"; the midrange (or interquartile interval) by the rectangular box; and the median $^{2}$, not the mean as discussed previously, by the central " $x$ ". This graphical approach provides a quick summary of central tendency, variability, and outliers. Figure 1 presents boxplots of detection, identification, and certain identification distance ordered by the arrow number given in table 1 . It also presents the effectiveness ratings for the ten different arrows. Inspection of these plots demonstrates generally that identification and certain identification distance in terms of median and range were greater for the two chevrons

2 The median is that data point for which half the data are larger and half are smaller. 
DETECTION DISTANCE (FT)

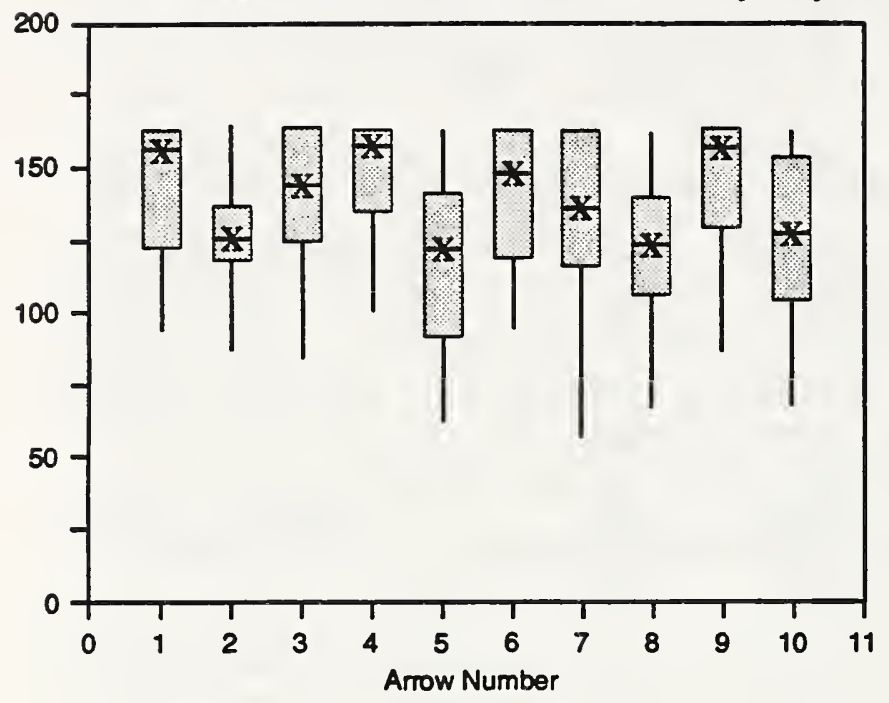

CONFIDENT DISTANCE (FT)

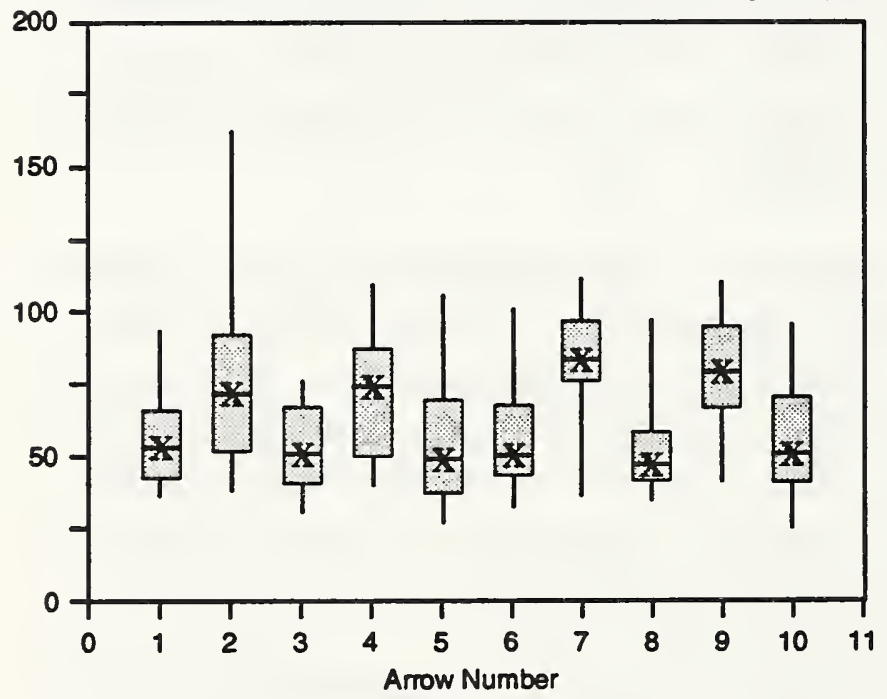

IDENTIFICATION DISTANCE (FT)

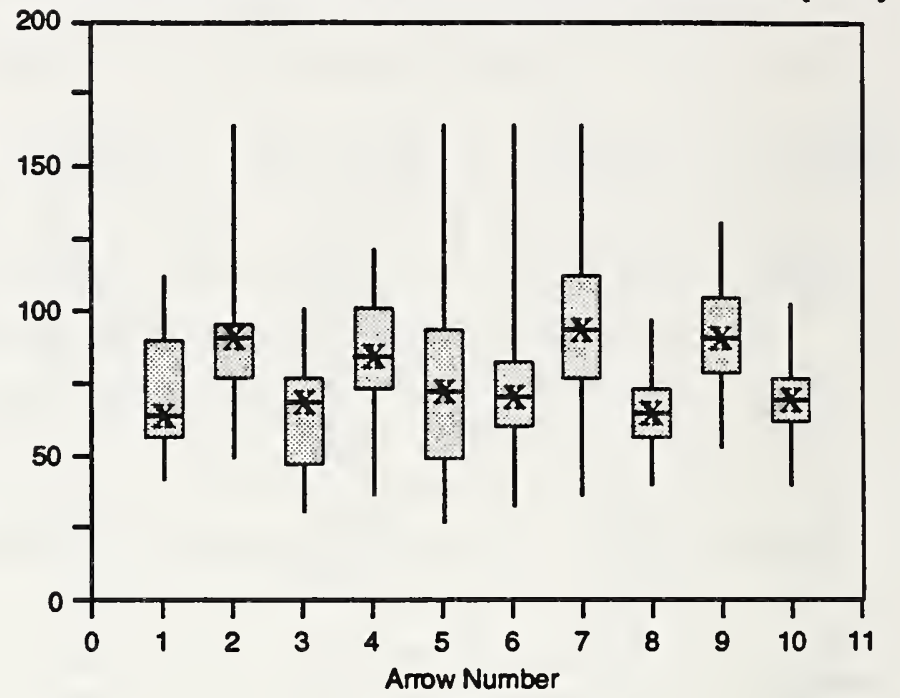

RATED EFFECTIVENESS

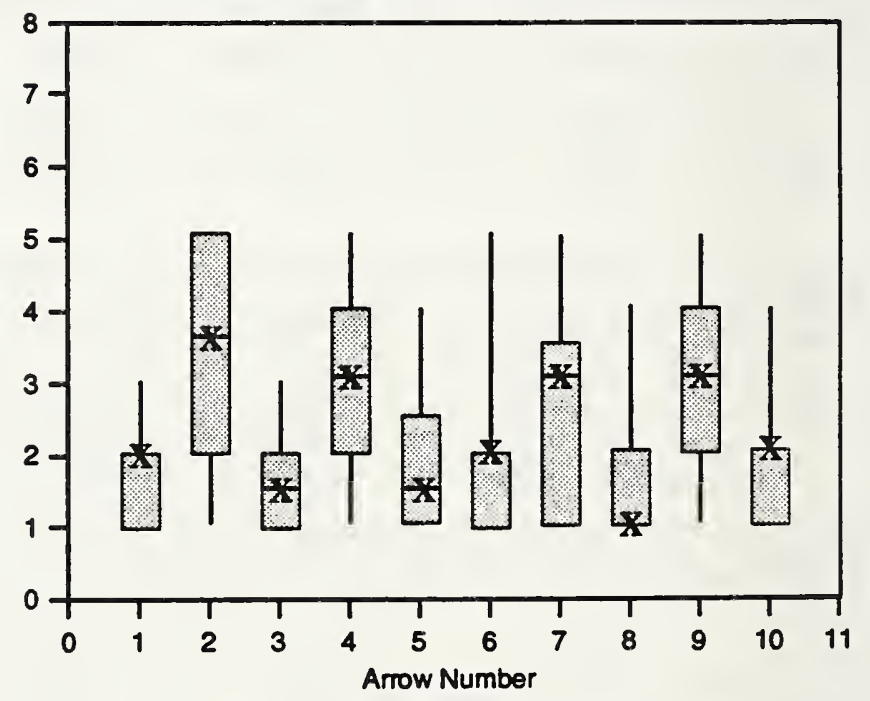

Figure 1. Boxplots of data for exit directional indicators from phase 1. 
(numbers 2 and 7), followed closely by the DOT arrows (numbers 4 and 9). Furthermore, effectiveness ratings were higher for the two chevrons. While there is considerable variability about the median, analyses of variance indicated that the differences between directional indicators in both mean identification distance and rated effectiveness were significant $(\mathrm{p}<.0001)$. The data in Table 1 indicate that chevrons were identified at the longest distance with substantially shorter distances for all other arrows except the DOT arrow. A Newman-Keuls multiple comparison test also revealed significant differences in identification distance between symbols 9, 2, 7 and all other symbols.

The next set of data describes the results for the words "EXIT" and "FKIT" alone. The word FKIT was chosen to be similar in appearance to EXIT so that observers would have to read the word, rather than just assume that any four letter word was "EXIT". Inspection of Table 2 reveals that the word EXIT was identified at a greater mean distance than the word FKIT -- $146 \mathrm{ft}$ versus $126 \mathrm{ft}$. Similarly, mean rated effectiveness was also greater (5.7 versus 5.1). Of interest is the fact that nine observers identified the word EXIT correctly at the maximum distance -- $164 \mathrm{ft}$. The shortest correct identification distances were 103 and $105 \mathrm{ft}$ indicating that the NFPA requirement of $100 \mathrm{ft}$ was effective for all 20 observers. The word FKIT was identified correctly from the maximum distance by seven people, while the shortest distance was between 61 and $63 \mathrm{ft}$.

The final set of results are for combinations of the word EXIT or FKIT and chevron. Table 2 presents these data grouped by the size of the directional indicator. Thus, the means and standard deviations for the 0.75 -in indicator are presented first, followed by those for 1.0 in, 1.75-in, 2.25-in, 3.5-in, and 4.25-in chevrons. Inspection of these data suggests that the combination of the smaller chevrons with the word EXIT (or FKIT) reduced the mean identification distance substantially from that obtained for the word alone or the 2.5-in chevron alone. Thus, the mean identification distance for the word plus a 0.75 -in chevron was $36 \mathrm{ft}$ with a standard deviation of 13.4 . The mean rating was 2.67 with a standard deviation of 1.7. The increase to a 2.25-in chevron increased mean identification distance beyond $100 \mathrm{ft}$ to about $106 \mathrm{ft}$. At the same time, the mean rating of effectiveness also increased to 4.98 , with a standard deviation of 1.2. Figure 2 presents boxplot data for the combination of words with chevrons of different sizes graphed as a function of chevron height. Figure 2 shows a substantial increase in identification distance, as well as confident identification distance and visibility rating, as chevron height increased at least up to 3.5-in. Figure 2 also reveals that the combination of the word plus a 2.25 -in chevron was identified correctly at about $100 \mathrm{ft}$-- as specified by NFPA, with a 1.75 -in chevron being identified correctly at only about $85 \mathrm{ft}$. Of interest, the visibility data (detection, identification, and confident identification) for the 3.5 and 4.25 -in chevrons were nearly equivalent, indicating that both were about equally visible at $130 \mathrm{ft}$. In contrast, signs with the very small chevrons -- below 1.5-in -- were rarely visible before about $50 \mathrm{ft}$.

Analyses of variance indicated a significant difference $(p<.0001)$ in detection distance as a function of both symbol shape and chevron size. The specific ANOVA models used in this report were BMDP (1989) one-way analyses on identification distance, ratings and 
Table 2. Summary Data for the Combination of Words and Chevrons

\begin{tabular}{|c|c|c|c|c|c|}
\hline \multirow{2}{*}{$\begin{array}{l}\text { Sign Description } \\
136 " \text { EXIT }\end{array}$} & \multicolumn{2}{|c|}{ Detect } & \multirow{2}{*}{$\frac{\text { Identify }}{146.1}$} & \multirow{2}{*}{$\frac{\text { Confident }}{134.8}$} & \multirow{2}{*}{$\begin{array}{r}\text { Rating } \\
5.7\end{array}$} \\
\hline & Mean & 158.0 & & & \\
\hline & Std & 12.3 & 19.9 & 20.6 & 1.1 \\
\hline \multirow[t]{2}{*}{14 6" FKIT } & Mean & 157.0 & 125.7 & 115.1 & 5.1 \\
\hline & Std & 12.7 & 34.7 & 37.3 & 1.3 \\
\hline \multirow[t]{2}{*}{$15>$ EXIT $0.75^{\prime \prime}$} & Mean & 110.2 & 34.5 & 33.7 & 2.6 \\
\hline & Std & 33.8 & 9.8 & 8.8 & 1.8 \\
\hline \multirow[t]{2}{*}{22 EXIT < $0.75^{\prime \prime}$} & Mean & 111.6 & 37.3 & 33.3 & 2.6 \\
\hline & Std & 32.5 & 13.6 & 8.3 & 1.8 \\
\hline \multirow[t]{2}{*}{$29<$ FKIT 0.75" } & Mean & 109.3 & 35.2 & 34.5 & 2.5 \\
\hline & Std & 28.9 & 9.8 & 8.3 & 1.8 \\
\hline \multirow[t]{2}{*}{36 FKIT > 0.75" } & Mean & 117.0 & 38.0 & 34.1 & 2.9 \\
\hline & Std & 29.2 & 18.3 & 7.3 & 1.9 \\
\hline \multirow[t]{2}{*}{$16<\operatorname{EXIT} 1.0 "$} & Mean & 129.0 & 46.2 & 46.0 & 2.8 \\
\hline & Std & 27.4 & 12.9 & 15.7 & 1.6 \\
\hline \multirow[t]{2}{*}{23 EXIT > 1.0" } & Mean & 123.1 & 53.6 & 47.5 & 2.8 \\
\hline & Std & 22.5 & 16.1 & 13.0 & 1.2 \\
\hline \multirow[t]{2}{*}{$30>$ FKIT 1.0" } & Mean & 122.3 & 47.7 & 46.2 & 2.8 \\
\hline & Std & 26.1 & 15.0 & 14.7 & 1.3 \\
\hline \multirow[t]{2}{*}{37 FKIT < 1.0" } & Mean & 119.1 & 56.0 & 49.3 & 2.9 \\
\hline & Std & 23.8 & 21.7 & 16.4 & 1.9 \\
\hline \multirow[t]{2}{*}{$17>$ EXIT $1.75^{\prime \prime}$} & Mean & 137.2 & 86.5 & 78.9 & 4.1 \\
\hline & Std & 20.7 & 28.2 & 28.4 & 1.3 \\
\hline
\end{tabular}


Table 2. Continued

\begin{tabular}{|c|c|c|c|c|c|}
\hline 24 EXIT > 1.75" & Mean & 143.7 & 89.7 & 79.2 & 4.4 \\
\hline & Std & 19.7 & 24.0 & 19.8 & 0.9 \\
\hline \multirow[t]{2}{*}{31 < FKIT 1.75" } & Mean & 131.1 & 83.0 & 76.3 & 3.6 \\
\hline & Std & 24.2 & 18.9 & 18.1 & 1.4 \\
\hline \multirow[t]{2}{*}{38 FKIT < 1.75" } & Mean & 138.9 & 84.4 & 75.7 & 4.9 \\
\hline & Std & 23.2 & 22.5 & 18.7 & 1.0 \\
\hline \multirow[t]{2}{*}{$18<$ EXIT 2.25" } & Mean & 146.1 & 101.7 & 92.1 & 4.9 \\
\hline & Std & 18.1 & 20.6 & 18.2 & 1.0 \\
\hline \multirow[t]{2}{*}{25 EXIT < 2.25" } & Mean & 152.1 & 114.5 & 103.2 & 5.0 \\
\hline & Std & 18.0 & 27.0 & 26.4 & 4.4 \\
\hline \multirow[t]{2}{*}{$32>$ FKIT $2.25^{\prime \prime}$} & Mean & 144.0 & 99.9 & 97.6 & 4.7 \\
\hline & Std & 23.2 & 27.7 & 26.6 & 1.4 \\
\hline \multirow[t]{2}{*}{39 FKIT > 2.25" } & Mean & 152.6 & 109.3 & 102.9 & 5.9 \\
\hline & Std & 20.3 & 25.4 & 21.5 & 1.1 \\
\hline \multirow[t]{2}{*}{$19>$ EXIT $3.5^{\prime \prime}$} & Mean & 154.8 & 138.0 & 121.8 & 6.0 \\
\hline & Std & 16.2 & 29.1 & 26.8 & 1.0 \\
\hline \multirow[t]{2}{*}{$20<$ EXIT 3.5" } & Mean & 155.1 & 138.6 & 130.3 & 5.9 \\
\hline & Std & 16.3 & 24.4 & 22.6 & 1.2 \\
\hline \multirow[t]{2}{*}{26 EXIT < 3.5" } & Mean & 156.1 & 142.3 & 127.5 & 6.2 \\
\hline & Std & 14.5 & 31.6 & 27.0 & 1.1 \\
\hline \multirow[t]{2}{*}{27 EXIT > 3.5" } & Mean & 156.5 & 138.6 & 126.7 & 6.2 \\
\hline & Std & 14.5 & 26.9 & 25.6 & 1.1 \\
\hline \multirow[t]{2}{*}{$33<$ FKIT 3.5" } & Mean & 152.5 & 118.8 & 110.4 & 5.8 \\
\hline & Std & 16.7 & 37.7 & 30.3 & 1.2 \\
\hline \multirow[t]{2}{*}{$34>$ FKIT $3.5^{\prime \prime}$} & Mean & 152.4 & 128.0 & 118.9 & 5.7 \\
\hline & Std & 20.2 & 31.5 & 28.7 & 1.2 \\
\hline
\end{tabular}




\begin{tabular}{|c|c|c|c|c|c|}
\hline \multirow[t]{2}{*}{40 FKIT > 3.5" } & Mean & 157.4 & 133.7 & 122.9 & 6.0 \\
\hline & Std & 15.2 & 33.4 & 28.3 & 0.9 \\
\hline \multirow[t]{2}{*}{41 FKIT < 3.5" } & Mean & 158.4 & 129.4 & 120.7 & 5.9 \\
\hline & Std & 11.7 & 28.6 & 25.1 & 1.2 \\
\hline \multirow[t]{2}{*}{$21>\operatorname{EXIT} 4.25^{\prime \prime}$} & Mean & 154.3 & 140.2 & 123.5 & 6.2 \\
\hline & Std & 18.4 & 28.1 & 26.0 & 0.7 \\
\hline \multirow[t]{2}{*}{28 EXIT $>4.25^{\prime \prime}$} & Mean & 156.7 & 144.7 & 133.4 & 6.3 \\
\hline & Std & 16.3 & 25.3 & 27.7 & 1.1 \\
\hline \multirow[t]{2}{*}{$35<$ FKIT $4.25 "$} & Mean & 153.1 & 119.2 & 114.6 & 5.9 \\
\hline & Std & 17.6 & 32.8 & 30.2 & 1.3 \\
\hline \multirow[t]{2}{*}{42 FKIT $<4.25^{\prime \prime}$} & Mean & 155.8 & 127.7 & 116.3 & 5.7 \\
\hline & Std & 17.4 & 32.7 & 28.5 & 1.2 \\
\hline
\end{tabular}


DETECTION DISTANCE (FT)

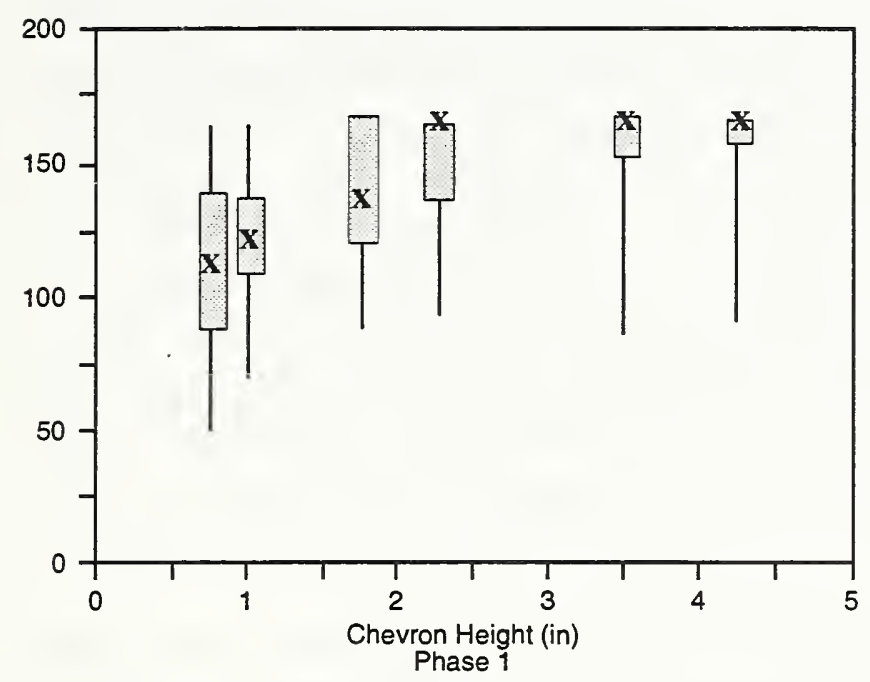

CONFIDENT DISTANCE (FT)

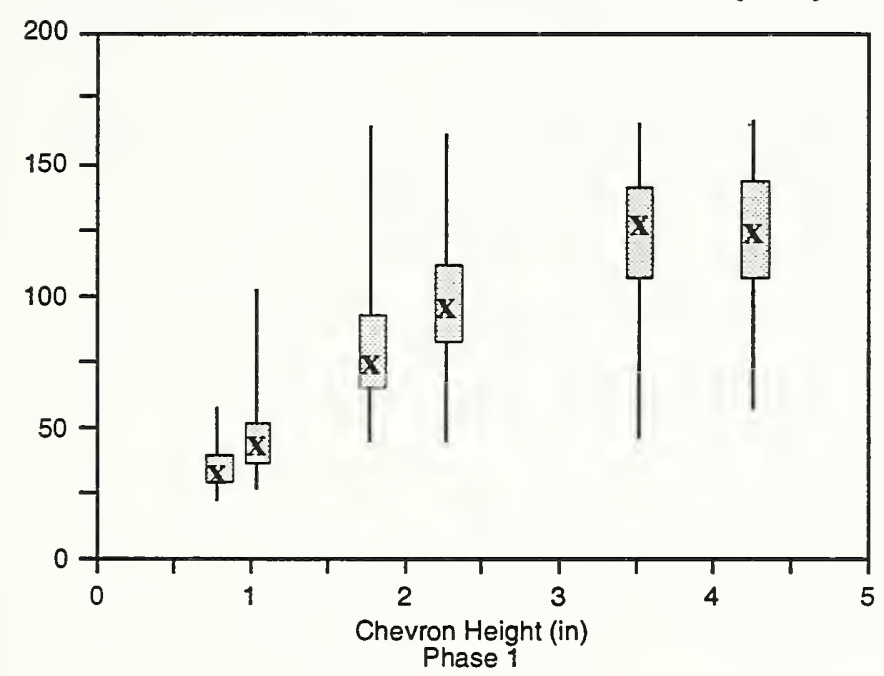

IDENTIFICATION DISTANCE (FT)

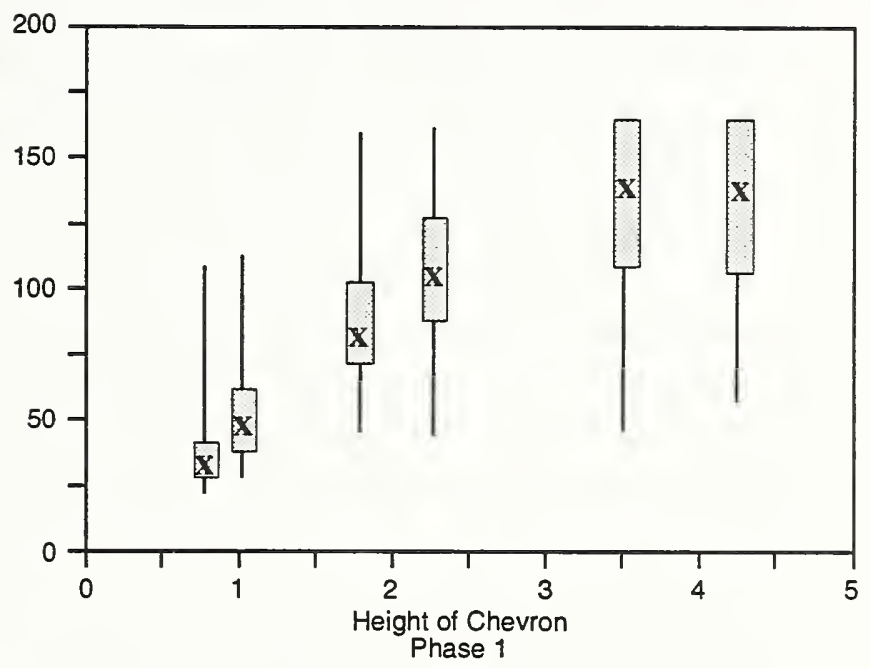

RATED EFFECTIVENESS

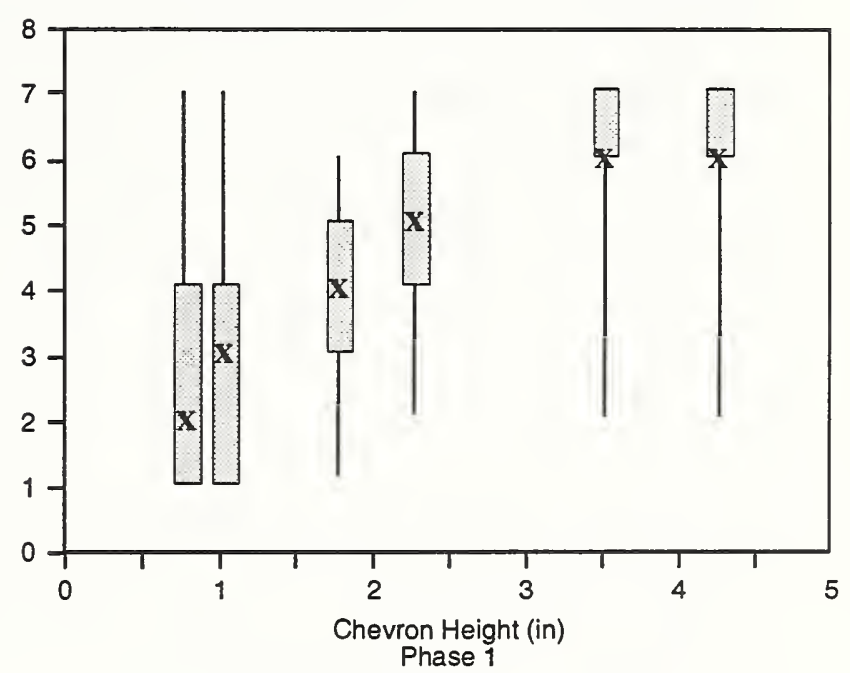

Figure 2. Boxplots of data for Exit words combined with chevrons from phase 1. 
speed, and to a lesser extent, two-way analyses on specific configurations such as size and color, or size and consistency. (Some one-way ANOVAs were done with Dataplot, and repeated with BMDP.) No higher order ANOVA models were used because of lack of data in some cells - not all possible examples of all sizes in all colors were tested. These analyses were supplemented by $\chi^{2}$ analyses and by multiple comparison tests such as Newman-Keuls from the BMDP program. Analyses of the differences in chevron location (left or right of the word), direction (left or right), and consistency were not significant, although there were many observer complaints about inconsistent direction. (An inconsistent chevron would be located on the left, but point right, for example.) There were also no significant differences between identification distances for the combinations of EXIT and FKIT with chevrons of different sizes. A Newman-Keuls test on identification distance as a function of size indicated that the ranges did not overlap for the 1.0, 1.75, and 2.25-in chevrons, and that the 3.5 and 4.25 -in chevrons formed a fourth non-overlapping group. Thus differences between the 1.0, 1.75, 2.25, and 3.5-in. chevrons were significant. These data indicate that larger chevrons tend to receive higher ratings and be visible at greater distances.

Data from phase 1 indicate that a 2.25 -in chevron was visible at $100 \mathrm{ft}$ and received adequate effectiveness ratings, while chevrons bigger than this were visible at distances beyond the NFPA $100 \mathrm{ft}$ requirement. Ratings of effectiveness closely paralleled the identification distance data. Frequency counts of the ratings were analyzed with a $\chi^{2}$ analysis which indicated significant $(p<.01)$ difference in the distribution of ratings as a function of chevron size. An analysis of variance was also significant $(p<.0001)$.

All signs were rated for effectiveness at $60 \mathrm{ft}$ - a distance selected for the rating data as a pragmatic compromise. When the project began there was some question as to whether 100 $\mathrm{ft}$ or some shorter distance was the appropriate distance from which the directional indicator ought to be seen. Tables 1 and 2 reveal that all word and directional signs were visible at $60 \mathrm{ft}$, indicating that $60 \mathrm{ft}$ is an appropriate distance for rating sign effectiveness. Data on rated effectiveness thus provides information about overall sign effectiveness in addition to visibility. Problems rating the signs at $60 \mathrm{ft}$ did not occur for any of the directional indicators, no matter how small, but did occur for the "exit" and "no smoking" symbols, which were not visible before about $30 \mathrm{ft}$. A comparison of tables 1 and 2 reveals that while directional indicators by themselves received low ratings, the combination of words and larger directional indicators received much higher ratings. Thus the word EXIT by itself received a mean rating of 5.7, while EXIT plus a 4.25 -in chevron received mean ratings of 6.2 and 6.3 (depending on chevron direction) suggesting that the chevron actually enhanced the visibility of EXIT. 


\section{Phase 2 - Behavioral Assessment}

In phase 2 the effectiveness of combinations of the word "EXIT" with chevrons of different size and color in guiding people through a corridor was explored using a different experimental approach. Phase 2 was a behavioral evaluation in which exit sign effectiveness was assessed in terms of number of confusions, time to identify a sign correctly, and time to move through an exit corridor. As in Phase 1, ratings of sign effectiveness were also obtained.

\subsection{Procedure for Phase 2}

For the behavioral assessment, a windowless corridor located in the Supply and Plant Building at NIST was used. Midway down the corridor were 2 doors, one to the left and one to the right. At the end of the corridor, another corridor was located to the left, two doors were located straight ahead, and a simulated corridor was located to the right. This configuration was intended to simulate two choice points with five possible exits. The corridor was lit at normal emergency lighting levels with three fixtures being illuminated - at the start, midway, and the end. Illuminance on the floor varied substantially from 2 to $150 \mathrm{~lx}$ depending on the placement of the fixtures. Illuminance on the floor was greatest (150 lx) at the beginning and midway down the corridor, and lowest (2 lx) between fixtures. Illuminance was only $29 \mathrm{~lx}$ on the floor at the end of the corridor. This was done so that the greater illuminance at the first set of doors might increase the likelihood of confusions. The exit sign was illuminated to $54 \mathrm{~lx}$, and located at the second choice point.

A total of 22 signs, in two groups of eleven each, was used in phase 2, although each subject saw only 11 signs (presented in random order), to reduce the time for the experiment. All signs were combinations of the word EXIT with a chevron, since the first experiment had evaluated the relative performance of EXIT and FKIT. Eight sizes of chevrons were used, ranging from 0.75 -in to 2.75 -in. Unlike phase 1 , eight signs were red on grey, eight were green on grey, while six were grey on white. Colors were evenly divided between each group of eleven signs. Contrast was about 0.45 for the grey signs; 0.5 for the red and green signs. All signs indicated directional information, either left or right, with a mixture of consistent and inconsistent chevrons.

Thirty-four observers participated with 17 observers viewing each set of 11 signs. Each set of signs included examples of all eight sizes in the three color combinations. An additional two observers were handicapped (one walked with a limp, while the other had low-vision (20-400 in one eye) - their data are included in only a few comparisons. Sixteen observers were female; 20 were male. The majority of the observers (79\%) wore some type of visual correction, either glasses or contact lenses. In terms of age, $23.5 \%$ were between 18 and $30,20.6 \%$ between 31 and $39 ; 38.2 \%$ between 40 and 49 ; and $17.6 \%$ between 50 and 59 . Finally, three observers reported mild color defects. 
For the behavioral phase, observers were instructed to move through the corridor, identify the sign when they could read it, and then turn in the direction indicated by the sign when they felt it was appropriate to do so. As noted earlier, the corridor was designed with five potential exit doors to provide an opportunity for confusions and to allow the observer to select an exit path that corresponded with the directional exit sign. The exit sign was located about $118 \mathrm{ft}$ from the starting point in the center of the corridor and about $6 \mathrm{ft}$ above the ground. External illuminance on the sign was maintained at about $54 \mathrm{~lx}$.

Observers were told that their time to move through the corridor was being recorded, but to move at their normal walking speed. Two different times were recorded - time to identify the sign, and time to move through the corridor. Measurement of time was accomplished by means of infra-red sensing devices which were activated when the observer first stepped into the corridor. A second set of sensors was located at the left and right turning points at the end of the corridor. When the observer stepped through the final set of beams, the electronic timer stopped, indicating the time to walk through the corridor in seconds. In addition, the experimenter stopped a second timer electronically when the observer identified the sign. This time was used as the basis for the identification data discussed below.

\subsection{Results for the Behavioral Assessment}

Several different types of results were obtained in the behavioral assessment. First, information on confusions and incorrect turns was collected. Second, the time to move through the corridor was obtained, with walking speed being determined as a function of time in the corridor. Third, information on identification distance was calculated as a function of identification time and sign distance. This procedure differs from the more direct measurement of identification distance used earlier. Finally, ratings of the effectiveness of the different signs using the 7-point scale used before were obtained, along with spontaneous comments from the participants.

The first set of data analyzed relates to confusions and incorrect turns. Data from only the first two of the eleven trials for each observer were included in this analysis since it was felt that the observers had learned the task by subsequent trials. A confusion was defined as an incorrect turn, usually at the center of the corridor or into the final set of doors located directly ahead. Analysis of the confusion data indicated that only 9 confusions occurred on the first 72 trials. Four confusions occurred for the exit sign with the 0.75 -in chevron, one each for the 1.0 and 1.5-in chevrons, two for the 1.75-in chevron, and one for the 2.25-in chevron. Thus, half the confusions occurred for the two smallest chevrons, whereas only one confusion occurred for the four chevrons larger than 1.75-in. The confusions that occurred on the first two trials were relatively limited and confined primarily to the smallest arrows or to "inconsistent" arrows, suggesting that subjects could not see the signs properly, not that they did not understand the task. Thus confusions were apparently related more to not being able to see the chevron or to mistaking the direction of travel than to misunderstanding the task. 
Inspection of the false positive data indicated that 14 false positives occurred in the behavioral st $\%$. These occurred when an observer said a sign faced left (or right) when it actually fa $d$ right (or left). Of the 14 occurrences, ten occurred for "inconsistent" chevrons, indicating that consistency was something expected by the observers. Eleven of the 14 false positives occurred for chevrons smaller than 2.25-in. Analyses of variance of the size and consistency factors for the rating data were significant for both $(p<.0001)$, as was a Newman-Keuls test. The ratings for "inconsistent" chevrons were significantly lower than those for the "consistent" chevrons. These data indicate that consistency of placement of the chevron relative to the intended direction is important to observers. Inconsistent chevrons appear likely to result in serious errors during emergency egress.

The difference in the time required to move through the corridor for the first trial as compared with the mean time for subsequent trials was also examined. The difference between the time for the first trial and for the average of all trials was calculated for each observer using his/her own average. In 30 of the 36 cases (the two handicapped observers were included since all data were normalized to the individual), the time on the first trial was greater than the average time. It was greater by as much as 5 to 15 seconds for 12 observers. In four cases, the time was shorter than the average, and in two cases observers turned early so their time could not be calculated. An examination of the mean difference between the first trial time and the average indicates that the time generally decreased from $6.15 \mathrm{sec}$ to $3.3 \mathrm{sec}$ as the chevron size increased from 0.75 -in to 2.75 -in with anomalies in this trend for the 1.75 -in and 2.25 -in chevrons. Nonetheless, the use of very small chevrons consistently resulted in slightly longer travel times.

The behavioral assessment also provided information on three other aspects of the combination of EXIT signs with chevrons. These included identification distance, time to walk through the corridor and make the correct turn, and ratings of sign effectiveness. Table 3 summarizes the mean identification distance, rated effectiveness, and speed to move through the corridor for the different signs as a function of chevron size for trials 3 to 11 - the ones for which observers were considered to have "learned" the task. The boxplot data are presented in Figure 3 for sign identification distance, time to move through the corridor, and rated effectiveness again for trials 3 to 11 .

Figure 3 confirms the trends found in phase 1; namely, that signs with larger chevrons were identified accurately at longer distances. Thus the combination of a 0.75 -in chevron with the word EXIT was identified accurately at a median distance of less than $40 \mathrm{ft}$, while signs with chevrons of 2.25 -in or greater were identified at median distances around $100 \mathrm{ft}$. The phase 2 data yielded shorter mean identification distances than phase 1 because the total length of the corridor was substantially shorter - $118 \mathrm{ft}$ as opposed to $160 \mathrm{ft}$. In phase 1 , a substantial number of observers could identify the sign from $160 \mathrm{ft}$ thus raising the overall average. Nvertheless, the means for the 2.25-in. green and red chevrons were close to 100 $\mathrm{ft}$ in phase 2. An analysis of variance indicated that the differences in identification distances as a function of chevron size were significant $(p<.0001)$. The first portion of Figure 3 indicates that the use of color had an impact on overall identification distance, with 
Table 3. Mean Identification Distance, Rating and Speed for Behavioral Phase

\begin{tabular}{|c|c|c|c|c|}
\hline Size & Color & $\begin{array}{l}\text { Identification } \\
\text { Distance }\end{array}$ & $\begin{array}{l}\text { Mean } \\
\text { Rating }\end{array}$ & $\begin{array}{l}\text { Mean } \\
\text { Speed }\end{array}$ \\
\hline \multirow[t]{3}{*}{0.75} & Green & 37.46 & 2.0 & 4.89 \\
\hline & Red & 40.68 & 2.69 & 4.74 \\
\hline & Grey & 35.38 & 1.4 & 4.76 \\
\hline \multirow[t]{3}{*}{1.0} & Green & 47.61 & 3.58 & 4.86 \\
\hline & Red & 49.41 & 2.73 & 4.93 \\
\hline & Grey & 39.38 & 2.36 & 4.88 \\
\hline \multirow[t]{2}{*}{1.25} & Green & 64.72 & 3.92 & 5.09 \\
\hline & Red & 53.26 & 3.33 & 4.83 \\
\hline \multirow[t]{2}{*}{1.5} & Green & 66.09 & 4.33 & 4.89 \\
\hline & Red & 83.96 & 4.71 & 5.10 \\
\hline \multirow[t]{3}{*}{1.75} & Green & 88.94 & 5.73 & 5.11 \\
\hline & Red & 73.63 & 4.18 & 4.8 \\
\hline & Grey & 72.87 & 2.71 & 5.24 \\
\hline \multirow[t]{2}{*}{2.0} & Green & 79.78 & 4.67 & 4.88 \\
\hline & Red & 91.69 & 5.25 & 5.01 \\
\hline \multirow[t]{3}{*}{2.25} & Green & 104.28 & 5.38 & 5.09 \\
\hline & Red & 96.16 & 5.25 & 5.01 \\
\hline & Grey & 76.15 & 3.60 & 4.88 \\
\hline \multirow[t]{2}{*}{0.75} & Green & 96.96 & 6.21 & 4.89 \\
\hline & Red & 100.20 & 5.76 & 5.16 \\
\hline $\begin{array}{l}\text { (two signs } \\
\text { used) }\end{array}$ & Grey & 93.23 & 4.26 & 5.05 \\
\hline
\end{tabular}


IDENTIFICATION DISTANCE

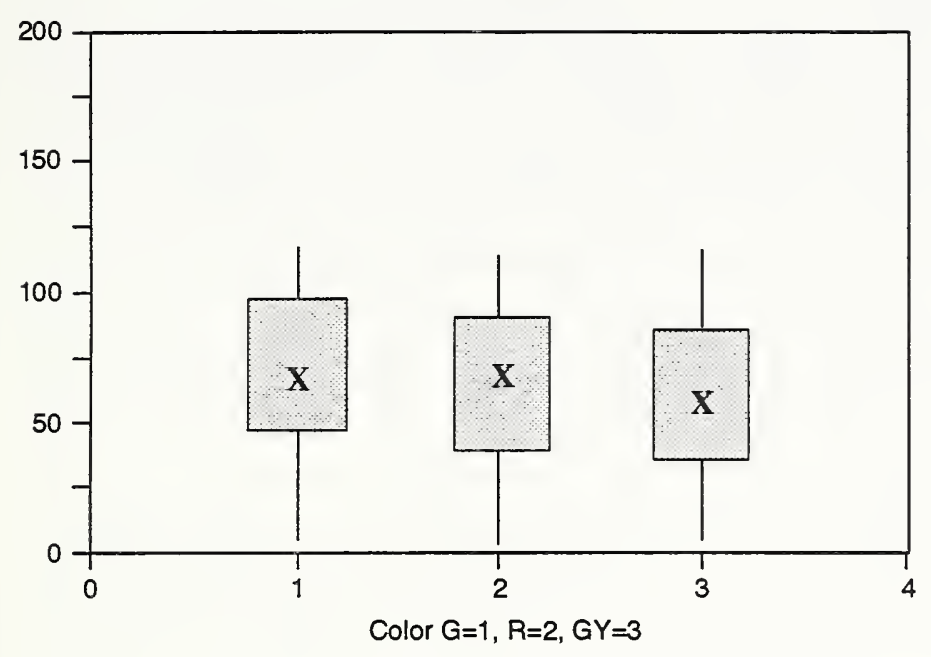

SPEED TO WALK CORRIDOR

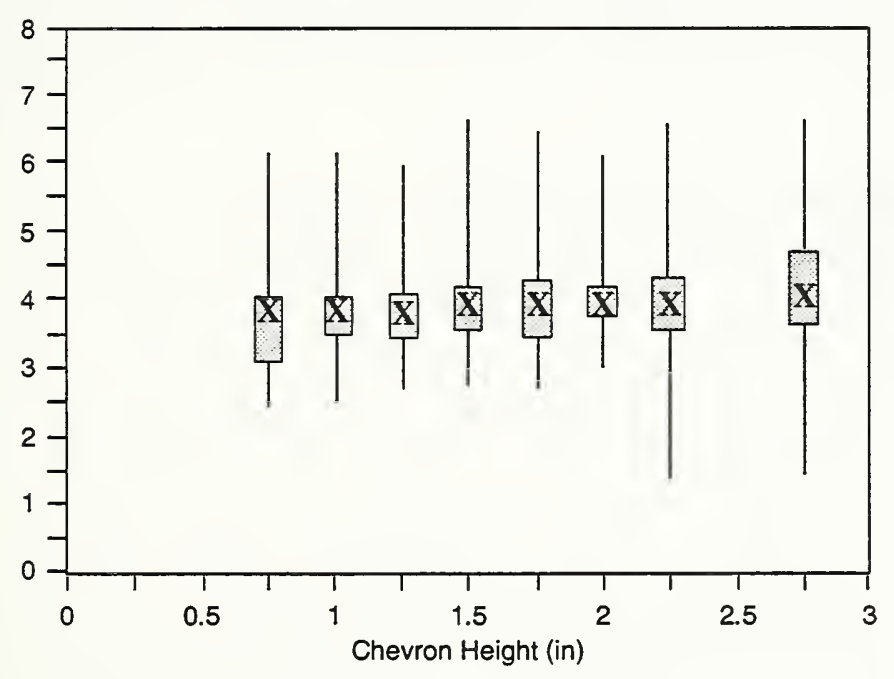

IDENTIFICATION DISTANCE

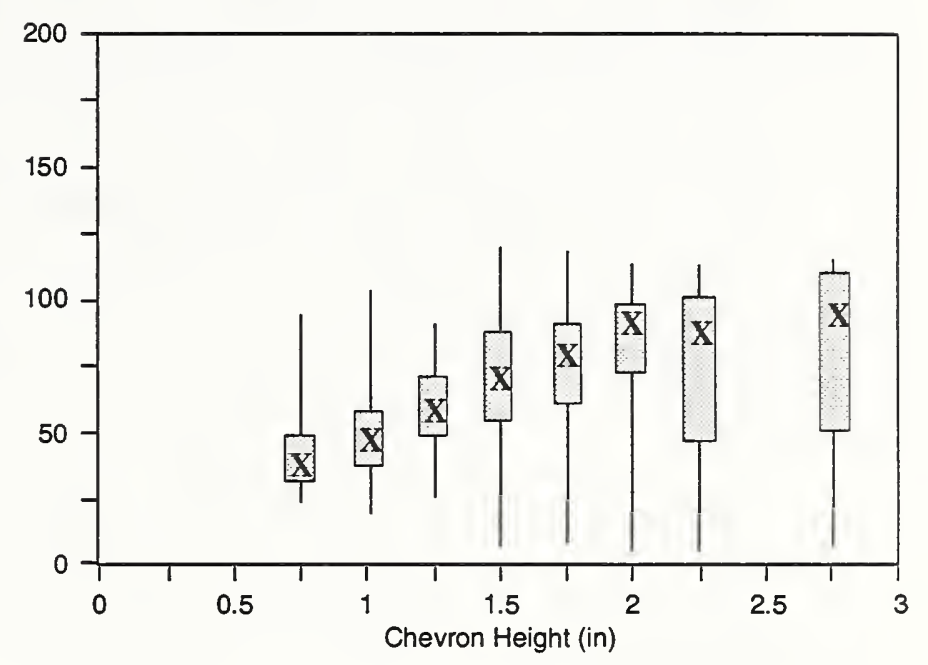

RATED EFFECTIVENESS

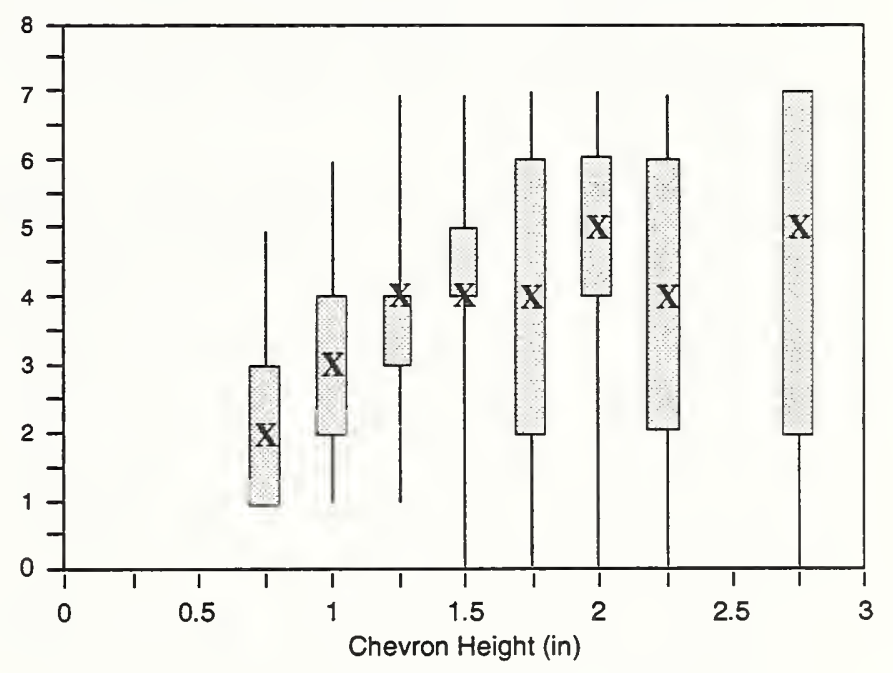

Figure 3. Boxplot of data for the behavioral assessment 
red and green signs identified at greater distances than grey signs. An analysis of variance indicated that the effect of color on identification distance was significant $(p<.01)$. Figure 3 also indicates that chevron size had little effect on the time to traverse the corridor - a finding confirmed by the analysis of variance.

There was a clear progression in ratings as chevron size increased when the data for the green and red signs were considered separately from the grey signs (which received very low ratings). Table 3 presents the mean data for this comparison. In fact, the rating data appear to be a more, rather than less, sensitive indicator of chevron effectiveness, in that they demonstrate a significant effect due to chevron characteristics. An analysis of variance for size was significant $(p<0.0001)$, as was a Newman-Keuls multiple comparison test $(p<.05)$. Nonetheless, it is true that the identification and rating data from all phases provide more clear-cut evidence of the visibility of chevrons than do the speed data from phase 2. The behavioral data provide valuable information on confusions and inconsistencies, all of which suggest that smaller chevrons are less effective, but they do not provide evidence that chevron size affects speed in a realistic exit corridor. A way-finding experiment in which people use chevrons to find their way out of a more complicated maze might provide more conclusive evidence of slower speeds and increased confusions due to chevron size.

Finally, Figure 3 indicates that ratings of the overall effectiveness of the sign increased as chevron size increased with signs with chevrons of 2.25 -in or greater receiving median ratings of 5 (on a 7-point scale), while signs with chevrons of 1 -in or less received median ratings below 3. A $\chi^{2}$ analysis of the difference in the distribution of the ratings for the two categories of chevrons was significant $(p<0.05)$. A $\chi^{2}$ analysis of the difference in the distribution of ratings for colored (red and green) signs versus grey signs was also significant $(\mathrm{p}<.01)$. There was no significant difference in the distribution of ratings between red and green signs, however.

Table 4 summarizes the percentages of spontaneous comments made by subjects during the behavioral evaluation. The full comments themselves are tabulated in Appendix A. The following eight categories were developed to describe and group the comments: $\mathrm{OK}$, not visible, too small, poor color, poor contrast, not consistent, bad design, and bad for behavior. Inspection of table 4 indicates clearly that size, consistency and color (or contrast) were important factors in subjects' perception of effective directional indicators. The signs considered to be "OK" were those with large, consistent chevrons in red or green. All the grey sign, even the ones with a 2.75 -in chevron were considered to have "poor color", "poor contrast", or "poor visibility". Similarly, chevrons smaller than 1.75-in in green or red were considered to be "too small" or "not visible". Consistency between placement of the chevron and the intended direction of travel was also an important factor with inconsistent signs rarely considered to be "OK". 
Table 4. Percentage of Spontaneous Comments Made During Behavioral Assessment

\begin{tabular}{|c|c|c|c|c|c|c|c|c|c|c|}
\hline Size & Cons & $\mathrm{OK}$ & $\begin{array}{l}\text { Not } \\
\text { Vsble }\end{array}$ & $\begin{array}{l}\text { Too } \\
\text { Small }\end{array}$ & $\begin{array}{l}\text { Poor } \\
\text { Color }\end{array}$ & $\begin{array}{l}\text { Poor } \\
\text { Cntrst }\end{array}$ & $\begin{array}{l}\text { Not } \\
\text { Cons }\end{array}$ & $\begin{array}{l}\text { Poor } \\
\text { Dsgn }\end{array}$ & Bhv & $\mathrm{N}$ \\
\hline \multicolumn{11}{|c|}{ GRAY } \\
\hline 0.75 & Inc & 0.0 & 38.5 & 23.1 & 7.7 & 7.7 & 15.4 & 7.7 & 0.0 & 13 \\
\hline 1.00 & Cons & 10.0 & 50.0 & 40.0 & 0.0 & 0.0 & 0.0 & 0.0 & 0.0 & 10 \\
\hline 1.75 & Inc & 0.0 & 0.0 & 9.1 & 9.1 & 27.3 & 27.3 & 27.3 & 0.0 & 11 \\
\hline 2.25 & Cons & 15.4 & 0.0 & 0.0 & 15.4 & 61.5 & 0.0 & 0.0 & 7.7 & 13 \\
\hline 2.75 & Inc & 7.7 & 0.0 & 0.0 & 23.1 & 38.5 & 23.1 & 3.8 & 3.8 & 26 \\
\hline \multicolumn{11}{|c|}{ RED } \\
\hline 0.75 & Cons & 0.0 & 45.4 & 36.4 & 0.0 & 0.0 & 0.0 & 9.1 & 9.1 & 11 \\
\hline 1.00 & Cons & 0.0 & 9.1 & 63.6 & 0.0 & 0.0 & 9.1 & 18.2 & 0.0 & 11 \\
\hline 1.25 & Inc & 0.0 & 25.0 & 50.0 & 8.3 & 0.0 & 8.3 & 8.3 & 0.0 & 12 \\
\hline 1.50 & Cons & 7.7 & 7.7 & 38.5 & 7.7 & 15.4 & 0.0 & 15.4 & 7.7 & 13 \\
\hline 1.75 & Inc & 23.1 & 0.0 & 0.0 & 15.4 & 0.0 & 61.5 & 0.0 & 0.0 & 13 \\
\hline 2.00 & Cons & 10.0 & 0.0 & 50.0 & 0.0 & 10.0 & 0.0 & 30.0 & 0.0 & 10 \\
\hline 2.25 & Cons & 75.0 & 0.0 & 12.5 & 12.5 & 0.0 & 0.0 & 0.0 & 0.0 & 8 \\
\hline 2.75 & Inc & 41.7 & 0.0 & 0.0 & 8.3 & 8.3 & 33.3 & 8.3 & 0.0 & 12 \\
\hline \multicolumn{11}{|c|}{ GREEN } \\
\hline 0.75 & Inc & 0.0 & 0.0 & 45.4 & 0.0 & 9.1 & 18.2 & 27.3 & 0.0 & 11 \\
\hline 1.00 & Cons & 0.0 & 33.3 & 33.3 & 8.3 & 8.3 & 0.0 & 16.7 & 0.0 & 12 \\
\hline 1.25 & Cons & 0.0 & 18.2 & 54.6 & 0.0 & 9.1 & 0.0 & 18.2 & 0.0 & 11 \\
\hline 1.50 & Inc & 14.3 & 7.1 & 28.6 & 0.0 & 7.1 & 42.9 & 0.0 & 0.0 & 14 \\
\hline 1.75 & Cons & 66.7 & 0.0 & 16.7 & 8.3 & 8.3 & 0.0 & 0.0 & 0.0 & 12 \\
\hline 2.00 & Inc & 23.1 & 0.0 & 15.4 & 7.7 & 7.7 & 46.2 & 0.0 & 0.0 & 13 \\
\hline 2.25 & Inc & 36.4 & 0.0 & 9.1 & 9.1 & 0.0 & 27.3 & 18.2 & 0.0 & 11 \\
\hline 2.75 & Cons & 90.0 & 0.0 & 10.0 & 0.0 & 0.0 & 0.0 & 0.0 & 0.0 & 10 \\
\hline
\end{tabular}




\section{Phase 3 - Follow-up Visibility Assessment}

\subsection{Procedure for Phase 3}

Because the behavioral assessment had raised questions about the role of color in determining sign visibility, a third experimental phase was conducted. In this phase, 15 observers viewed 14 combinations of the word EXIT with a chevron using the same experimental procedure as the initial visibility assessment in phase 1 . Observers indicated when they could detect and identify each sign, and rated it using the seven-point effectiveness scale. Six signs were the red and green signs from phase 2, two were grey on white signs from phase 1 , and six were new signs designed to assess the effect of variations in chevron configuration. For the six new signs, the ratios of height to width (aspect ratio) as well as total area were varied as shown in table 5. Aspect ratio was increased beyond the 1.20 used in phase 1 . Fifteen observers participated with $20 \%$ aged 18 to $25 ; 20 \%$ aged 26 to $30 ; 13 \%$ aged 31 to $39 ; 26 \%$ aged 40 to 49 ; and $20 \%$ aged 50 to 59. Ten were male; five were female. Seven required corrective lenses, and two reported mild color defects.

\subsection{Results for Phase 3}

Table 5 indicates that the mean detection and identification distances as well as effectiveness ratings increased consistently with chevron size for the red and green signs from $71 \mathrm{ft}$ for a 1.3-in red sign to $136 \mathrm{ft}$ for a 2.75 -in green sign. Comparison with Table 2 reveals that mean identification distance and effectiveness ratings were substantially greater for the colored signs than for comparably sized grey signs. Thus, grey EXIT signs (signs 17 and 24 in Table 2) with a 1.75-in chevron were identified at 86-89 ft and given mean ratings of 4.1 and 4.4, while a similarly sized green sign (sign 110) was identified at $100 \mathrm{ft}$ and given a mean rating of 5.3 as shown in Table 5. Similarly, grey signs with a 2.25 -in chevron (18 and 25) were identified at mean distances of 101 and $114 \mathrm{ft}$ with mean ratings of 4.9 and 5.0 while a 2.25 -in red sign (113) was identified at a mean distance of $126 \mathrm{ft}$ and given a much higher mean rating of 6.2 .

Figure 4 presents boxplot data for detection and identification distance as well as ratings as a function of chevron height. It demonstrates that increasing chevron height did not always lead to increased identification distance or higher rated effectiveness. The upper plot in figure 5 indicates further that mean identification distance did not vary systematically as a function of chevron width. Increasing chevron height, but decreasing width was not particularly successful in increasing identifiability. Thus as indicated in table 5, the sign with the 1.75-in conventional chevron in green was identified at a mean distance of $100 \mathrm{ft}$ while the 1.75 -in chevron with a greater width (sign 512) was identified at only $65.7 \mathrm{ft}$ (and given a mean rating of 2.7). Its performance was also poorer than that for the comparable grey on white signs (17 and 24 in Table 2) discussed above. Table 5 reveals that signs 511 and 513 (with a 2.25-in high chevrons but narrower widths and aspect ratios above 1.2) 
Table 5. Visibility Data for Phase 3

\begin{tabular}{|c|c|c|c|c|c|c|c|c|}
\hline \multirow{3}{*}{$\frac{\text { Sign ID }}{16}$} & \multicolumn{4}{|c|}{ Chevron Characteristics } & \multicolumn{4}{|c|}{ Observer Responses } \\
\hline & \multirow{2}{*}{$\begin{array}{l}\text { Height } \\
1.3\end{array}$} & \multirow{2}{*}{$\begin{array}{l}\text { Width } \\
0.84\end{array}$} & \multirow{2}{*}{$\begin{array}{l}\text { Area } \\
0.38 \\
\end{array}$} & \multirow{2}{*}{$\begin{array}{l}\text { Color } \\
\text { Grey }\end{array}$} & \multicolumn{2}{|c|}{ Detection } & \multirow{2}{*}{$\begin{array}{r}\text { Identify } \\
58.8\end{array}$} & \multirow{2}{*}{$\frac{\text { Rating }}{2.3}$} \\
\hline & & & & & Mean & 110.9 & & \\
\hline & & & & & Std & 34.9 & 18.1 & 4.8 \\
\hline \multirow[t]{2}{*}{105} & 1.3 & 1.06 & 0.57 & Red & Mean & 130.9 & 71.0 & 4.8 \\
\hline & & & & & Std & 33.3 & 13.4 & 1.1 \\
\hline \multirow[t]{2}{*}{108} & 1.5 & 1.25 & 0.75 & Green & Mean & 139.3 & 81.7 & 4.8 \\
\hline & & & & & Std & 30.1 & 16.2 & 1.3 \\
\hline \multirow[t]{2}{*}{110} & 1.75 & 1.50 & 1.09 & Green & Mean & 142.1 & 100.5 & 5.3 \\
\hline & & & & & Std & 24.1 & 27.1 & 1.2 \\
\hline \multirow[t]{2}{*}{111} & 2.0 & 1.69 & 1.38 & Red & Mean & 151.7 & 112.5 & 5.9 \\
\hline & & & & & Std & 18.8 & 24.7 & 1.2 \\
\hline \multirow[t]{2}{*}{113} & 2.25 & 1.86 & 1.69 & Red & Mean & 151.7 & 126.7 & 6.2 \\
\hline & & & & & Std & 22.8 & 27.2 & 1.3 \\
\hline \multirow[t]{2}{*}{17} & 1.5 & 1.50 & 1.09 & Grey & Mean & 130.9 & 88.1 & 3.7 \\
\hline & & & & & Std & 26.3 & 28.1 & 1.5 \\
\hline \multirow[t]{2}{*}{116} & 2.75 & 2.50 & 2.58 & Green & Mean & 158.3 & 36.2 & 5.9 \\
\hline & & & & & Std & 12.9 & 24.5 & 1.1 \\
\hline \multirow[t]{2}{*}{512} & 1.75 & 0.62 & 0.44 & White & Mean & 111.5 & 65.7 & 2.7 \\
\hline & & & & & Std & 38.0 & 17.8 & 1.6 \\
\hline \multirow[t]{2}{*}{511} & 2.25 & 1.12 & 0.91 & White & Mean & 134.2 & 87.0 & 3.5 \\
\hline & & & & & Std & 23.1 & 14.9 & 1.7 \\
\hline \multirow[t]{2}{*}{514} & 3.0 & 0.88 & 1.19 & Grey & Mean & 139.6 & 98.9 & 4.0 \\
\hline & & & & & Std & 26.2 & 26.7 & 1.9 \\
\hline \multirow[t]{2}{*}{201} & 3.75 & 1.12 & 2.03 & Grey & Mean & 134.9 & 104.3 & 4.8 \\
\hline & & & & & Std & 30.9 & 27.9 & 1.3 \\
\hline \multirow[t]{2}{*}{202} & 2.6 & 1.12 & 1.53 & Grey & Mean & 136.0 & 102.0 & 4.5 \\
\hline & & & & & Std & 25.8 & 28.3 & 1.6 \\
\hline \multirow[t]{2}{*}{513} & 2.25 & 0.88 & 1.12 & White & Mean & 139.9 & 86.0 & 3.1 \\
\hline & & & & & Std & 25.4 & 16.2 & 1.5 \\
\hline
\end{tabular}




\section{IDENTIFICATION DISTANCE (FT)}

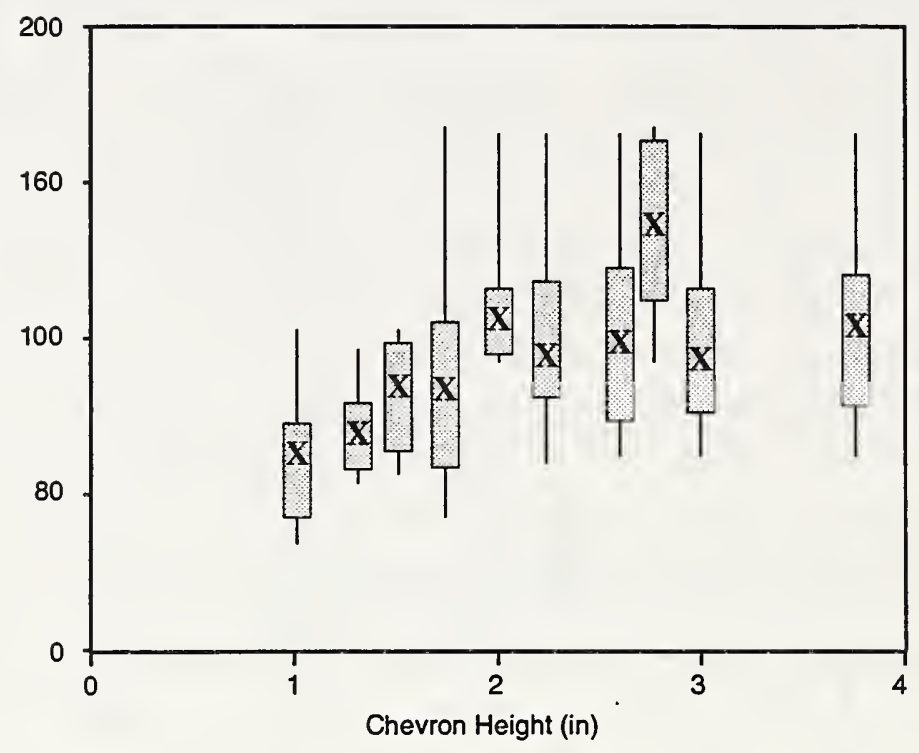

RATED EFFECTIVENESS

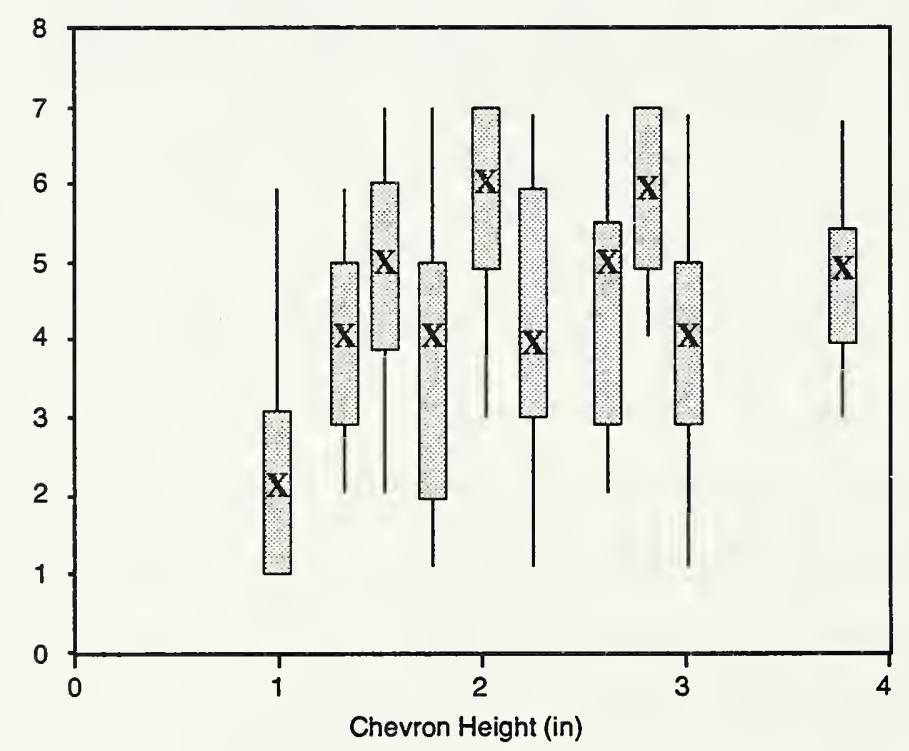

Figure 4. Box plots of identification distance and ratings as a function of chevron height for the data from phase 3. 
were identified at $87 \mathrm{ft}$ and $86 \mathrm{ft}$ (with mean ratings of 3.5 and 3.1) whereas the 2.25-in grey signs assessed in phase 1 (18 and 25) were identified at 102 and $114 \mathrm{ft}$. In contrast, the 2.25 -in red sign with the same aspect ratio (1.2) was identified at about $127 \mathrm{ft}$ as shown in Figure 4. These comparisons suggest that the "conventional" chevron was more effective than the one in which width was decreased. Chevron height had to be increased to at least 2.6-in, when width was decreased, to maintain visibility at the $100 \mathrm{ft}$ viewing distance.

Figure 5 presents a possible explanation for this effect. In the first of these plots, no systematic relationship was revealed when mean identification distance was plotted as function of chevron width. Yet when mean identification distance was plotted as a function of total chevron area $\left(\mathrm{in}^{2}\right)$, rather than width, mean identification distance increased systematically as shown in both lower plots of Figure 5. In fact, chevron area appears to be a better predictor of sign visibility than height or width alone. Area was defined as the actual area occupied by the arrow, not the smallest rectangle. This suggests that the predictability of calculated visibility as a function of visual angle, such as presented by Howett (1983), might be improved if total area were used instead of height. The lower plots in Figure 5 compare the mean identification distance data for the red and green chevrons with that for the grey chevrons from both phases 1 and 3, and demonstrate the color effect discussed above; namely, that the green and red chevrons were visible at greater distances than the grey and white ones. Thus, to be identified at $100 \mathrm{ft}$, grey arrows required an area of $1.19 \mathrm{in}^{2}$, while red and green arrows required only $1.09 \mathrm{in}^{2}$. While there was a contrast difference ( 0.45 for grey versus 0.5 for color), this does not seem to account fully for the differences in visibility distance. Analyses of variance for identification distance both as a function of size and of color were significant $(p<.001)$.

\section{Discussion and Conclusions}

Data from the three phases indicate a number of important conclusions about the visibility of exit signs and exit directional indicators. First, the chevron was the most visible indicator (followed closely by the DOT-AIGA arrow) in the present set of studies. Second, chevron characteristics such as height, width, and total area had an important influence on sign visibility, with larger chevrons identified accurately at greater distances. Third, the combination of the EXIT word with a chevron was identified at $100 \mathrm{ft}$ if the chevron was at least 2.25 -in high for the grey and white $(0.45$ contrast $)$ configuration. If chevron width was reduced, chevron height had to be increased to at least 2.6-in for adequate visibility at $100 \mathrm{ft}$. For grey and white signs, increases in chevron size beyond 3.5-in had little impact on mean identification distance or rated effectiveness. When a red or green configuration (with 0.5 contrast) was used, however, the chevron size could be reduced. Thus, chevron sign combinations were identified at $100 \mathrm{ft}$ for chevrons of 1.75 -in, with little increase between 2.25 and 2.75-in chevrons in terms of either identification distance or rated effectiveness. When color was used, mean identification distance for the 2.25 -in chevrons increased by about $25 \mathrm{ft}$ to approximately $125 \mathrm{ft}$. Nevertheless, data from the "low vision" observer indicated that even these larger chevrons (in green or red) were visible to her only about 10 to $15 \mathrm{ft}$. before the exit sign. Her data provide some insight into the limitations 


\section{DISTANCE TO SIGN}

Mean Identification

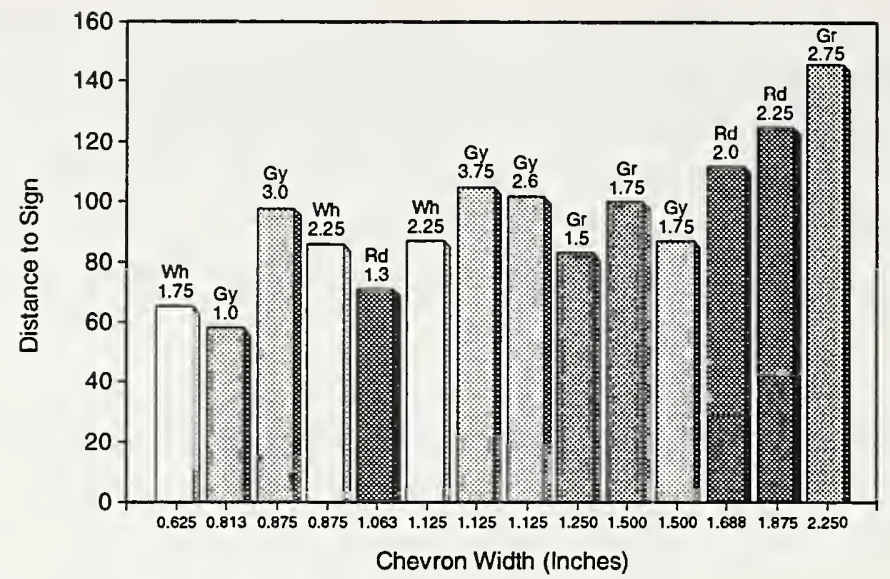

DISTANCE TO SIGN

Mean Identification

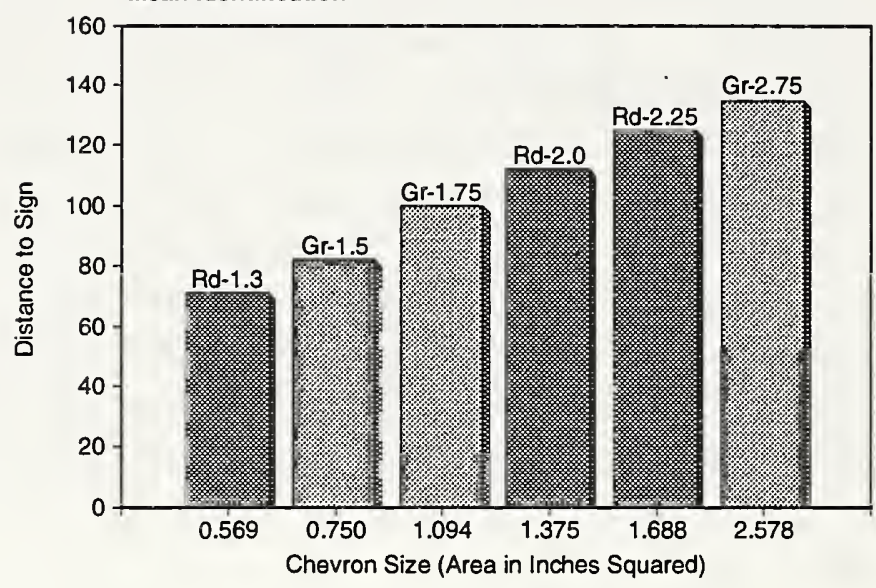

AVERAGE DISTANCE TO IDENTIFICATION All Grey Signs

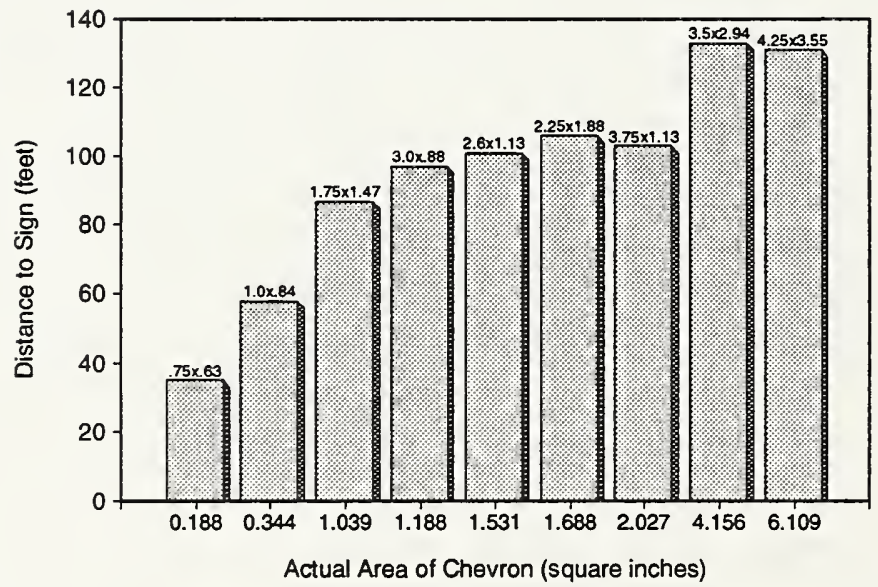

Figure 5. Mean identification distance as function of chevron width for chevrons in phase three, and as a function of area for red and green signs from phase 1, and grey signs from both phases 1 and 3 . 
suffered by handicapped building occupants and reinforce the need for minimum height, contrast, and color suggestions in the design of exit signs.

Questions still remain about the relative effects of color and contrast on sign identifiability, since there were differences in contrast, as well as color between the grey, red and green signs. Because the differences in contrast were small ( 0.1 or less), the data suggest that the use of color was an important factor in increasing sign visibility and perceived effectiveness. The behavioral data, while quite weak, tended to confirm these trends. Slower walking speeds, shorter identification distances, lower mean ratings, and more negative comments were seen in the behavioral assessment for the smaller chevrons, particularly those in grey with heights below about 1.75 or 2 -in. The data also suggested that consistency in the direction of travel with the placement of the indicator was important to the observers. In the two visibility assessments, signs with a consistent direction of travel were identified at slightly greater distances and given higher ratings somewhat more frequently, while in the behavioral assessment numerous negative comments were volunteered about "inconsistent" chevrons.

The analyses of variance revealed no statistically significant difference between directional indicators pointing left or right in Phases 1 and 3, although there was a tendency for right facing indicators to be seen at somewhat greater distances. The detection distance for the large chevrons was markedly shortened in Phase 2 because the data were limited by the shorter total length of the corridor $(118 \mathrm{ft})$. Because identification distances could not be greater than $118 \mathrm{ft}$, this effectively reduced the mean viewing distance below that for phases 1 and 3 where some observers identified the large chevrons at $164 \mathrm{ft}$. Identification distances obtained in phases 1 and 3 for identical signs were in fact very similar.

Finally, placement of the exit sign correctly with respect to architectural features is quite important. In the behavioral assessment people clearly expected the exit sign and attendant arrow to be located near the actual exit. The arrow was an enhancement to the sign that they considered to apply at the same location as the sign. The whole sign was perceived as an integral unit. Furthermore, observers were guided by the obvious presence of corridors and doors at the exit sign location. As a result, the behavioral assessment was not particularly successful in demonstrating a strong differential effect of variations in chevron size in creating confusions at exit choice points. Although observers successfully followed the directions given by the chevron, they expressed a desire to see the entire sign at the beginning of the corridor, and not see the chevron initially as a dot or blob near the word.

The data raise almost as many questions as they answer. For example, if contrast were increased above 0.5 or if color were used, the distance to identification would likely increase (as happened in the switch from grey to red and green signs). If internally lit signs were used, identification distance might also increase. The effects of increasing contrast, color, type and amount of illumination should be assessed parametrically in subsequent research since each of these variables appeared to influence detection distance in the present research. In addition, the data suggest that chevron height and width ratios can be varied 
to meet the $100-\mathrm{ft}$ visibility criterion, although chevrons with aspect ratios greater than 1.2 must be significantly taller. Further research should be done to determine the point at which varying parameters such as size, shape, aspect ratio, luminance, color and contrast no longer increase effective visibility.

Based on the data obtained from the three phases, it appears reasonable to recommend the use of chevrons with at least a 1.75 or 2.0 -in minimum height and preferably 2.25 -in for visibility with the word EXIT at $100 \mathrm{ft}$ for signs which meet the NFPA recommended minimums for contrast. The data suggest, however, that using color (or increasing contrast) can increase the identification distance such that 1.75 or 2.0-in chevrons are visible at 100 $\mathrm{ft}$. They also indicate that if chevron width is decreased, a height of 2.6-in appears to be a reasonable minimum chevron size for visibility at $100 \mathrm{ft}$. 
6. References

1. Collins, B.L. and Lerner, N.D. Evaluation of Exit Symbol Visibility. NBSIR 83-2675, March 1983.

2. Filliben, J.J. Dataplot - An Interactive High-Level Language for Graphics, Non-Linear Fitting, Data Analysis and Mathematics. Computer Graphics, 1981, 15, pp. 199-213.

3. Howett, G.L. Size of Letters Required for Visibility as a Function of Viewing Distance and Observer Visual Acuity. NBS Technical Note 1180, July 1983.

4. Lerner, N. D. Evaluation of Exit Directional Symbols, NBSIR 81-2268, May 1981.

5. McNeil, D.R. Interactive Data Analysis: A Practical Primer. New York: Wiley and Sons, 1977.

6. National Fire Protection Association (NFPA). Life Safety Code, NFPA, 101. Section 5-8, Illumination of Means of Egress; 5-9 Emergency Lighting; 5-10; Markings of Means of Egress. $1988 \mathrm{Ed}$.

7. Underwriter's Laboratory Inc. Report of Determination of Shape, Size and Visibility of Directional Arrows for Exit Signs (Report No. 1988-1, Subject 924). Underwriters Laboratories, Santa Clara, CA. March 1988. Report No. 1988-2, Subject 924), March 1988.

8. Young, W. Evaluation of Different Directional Symbols used with Exit Legend. Phases 1A and 1B. Lithonia Emergency Systems Internal Reports, Dec 20, 1988 and March 15, 1989. Evaluation of Directional Exit Signage, Phase II, November 10, 1989.

9. BMDP, BMDP Statistical Software, Los Angeles CA, Program version 1988, release date 1989. 
Appendix A. Comments Made by Subjects During Behavioral Evaluation

Sign 22 GRAY - 0.75 - Left Inconsistent

Observer Number

Too hard to see; don't know where you're going 23

Had to be at sign to see it 3

$\begin{array}{lr}\text { Could barely see it } & 19\end{array}$

Arrow too small $\quad 7$

Too hard to see $\quad 13$

Color poor, can't even hardly see arrow 25

$\begin{array}{ll}\text { Pitiful } & 29\end{array}$

Don't like arrow on side away from direction it points

-- color, size; Arrow location all poor $\quad 15$

Need 2 carets - needs darker background. 17

$\begin{array}{ll}\text { Dull -- Arrow too small } & 27\end{array}$

Worst yet; color very important; Arrow too small 21

$\begin{array}{ll}\text { Very confusing } & 33\end{array}$

$\begin{array}{ll}\text { No contrast; Arrow almost indistinguishable } & 11\end{array}$

$\underline{\text { Sign } 16 \text { GRAY - } 1.0 \text { - Left - Consistent }}$

Hard to see -- color no good -- looks like pencil 20

See exit but not arrow $r$

See EXIT; can't see Arrow $\quad 26$

$\begin{array}{lr}\text { Too light; arrow painfully small } & 10\end{array}$

Real light; couldn't see arrow until right on it 14

Nasty, poorly visible even under word; direction of travel poor $\quad 12$

$\begin{array}{ll}\text { Arrow on correct side } & 28\end{array}$

Never saw Arrow -- cannot see an arrow at all even when right under sign $\quad 34$

Hard to see arrow $\quad 36$

$\begin{array}{lr}\text { Arrow too small, no contrast in right position } & 16\end{array}$

Sign 17 GRAY - 1.75 - Right - Inconsistent

Colors not very bright - symbol too close to letters

-- Arrow should be consistent w/direction of travel

$\begin{array}{ll}\text { Caret bigger -- wrong side -- difficult to read on white background } & 17\end{array}$

$\begin{array}{ll}\text { Not very legible or attention getting } & 15\end{array}$

$\begin{array}{ll}\text { Dim arrow; too small } & 21\end{array}$

Not a good color; confused about direction of travel 13

$\begin{array}{ll}\text { Arrow not distinguishable; not as vivid } & 11\end{array}$

Grey is dull -- Arrow too close to E 25

Arrow too close to E -- Arrow inconsistent 29

Poor contrast 
Sign 17 GRAY - 1.75 - Right - Inconsistent (continued)

Don't like color at all 31

Need horizontal line with arrow 33

Sign 18 GRAY - 2.25 - Left - Consistent

Arrow bigger $\quad 28$

Tried to turn into file cabinet 36

$\begin{array}{ll}\text { Contrast too low } & 16\end{array}$

Contrast very poor; could see arrow eventually 34

$\begin{array}{lr}\text { Too light } & 10\end{array}$

Color bad 18

Too dull 26

Color not as predominant $\quad 20$

Size right, color doesn't catch eye $\quad 22$

Grey hard to visualize $\quad 14$

Directional indicator larger; visibility of whole sign poor $\quad 12$

Good size $\quad 8$

$\begin{array}{ll}\text { Not used to green } & 6\end{array}$

$\underline{\text { Sign } 19 \text { GRAY - 2.75 - Right - Inconsistent }}$

Arrow right size -- wrong side; color poor $\quad 6$

$\begin{array}{lr}\text { Too light; right arrow on left is bad } & 10\end{array}$

$\begin{array}{ll}\text { Color } & 20\end{array}$

$\begin{array}{lr}\text { See easily -- contrast not as great as would like } & 16\end{array}$

Closer arrow should be different color 8

Bigger; stands out; different $\quad 12$

Darker 2

Bad idea to have Arrow on wrong side -- confusing 34

$\begin{array}{ll}\text { Arrow good } & 36\end{array}$

$\begin{array}{ll}\text { Not as good; fluorescent better } & 21\end{array}$

Visibility real poor even though arrow bigger 26

Red easier to see than green or black $\quad 24$

Color doesn't stand out $\quad 28$

Not as clear $\quad 30$

$\begin{array}{ll}\text { Forget to turn right } & 32\end{array}$

Could not have seen if didn't know (EXIT) very poor contrast 34

$\begin{array}{ll}\text { Bad color - caret ok } & 18\end{array}$ 
Need a different color

Dull -- confused by placement of arrow; misleading 25

$\begin{array}{lr}\text { Prefer arrow on other side } & 7\end{array}$

$\begin{array}{lr}\text { Caret bigger, but on wrong side -- color should be brighter } & 17\end{array}$

Not right colors -- more easily read 15

Poor contrast $\quad 5$

$\begin{array}{lr}\text { Color not bright } & 19\end{array}$

Arrow big, don't like color -- not very effective 27

Needs contrast; (is too dull); doesn't grab attention 11

Sign 101 RED - 0.75 - Left - Consistent

Longest to see

Assume must go straight until see arrow too late

- In emergency arrow might be overlooked

Exit fine, couldn't tell what direction to go

Arrow too small

Tried to go straight

Arrow confusing

Couldn't see caret

Arrow too small

Not striking -- couldn't tell when to turn

Arrow too close to letters

Arrow too small

\section{Sign 102 GREEN - 0.75 - Right - Inconsistent}

Arrow impossibly small

Not clear sign indicated direction

Arrow real bad

Good contrast in either direction

Want to see Arrow just as easy as exit, arrow terrible

Caret needs to be on other side

Arrow too small -- would go straight through door \& not turn when I should.

- Arrow is smaller; more difficult

Arrow should be bigger

Good color; Arrow way too small; misleading

Wrong arrow

Arrow too tiny 
Sign 103 RED - 1.0 - Right - Consistent

Poor to see; need arrow on opposite side 33

Arrow bigger 25

Don't like color -- Arrow so small -- doesn't catch your eye 27

Exit ok; can't see arrow 11

Arrow too small 5

Exit easy -- caret too small -- wrong side -- would have to be closer to exit door

Arrow crummy -- exit good 29

Size of Arrow $\quad 19$

Size of arrow very difficult $\quad 15$

Kind of lousy. Arrow important to quickly learning what to do. 21

$\begin{array}{ll}\text { Prefers bigger arrow; easy color to see } & 13\end{array}$

Sign 104 GREEN - 1.0 - Right - Consistent

Arrow too small $\quad 30$

Red more outstanding $\quad 22$

$\begin{array}{ll}\text { Like darker color -- arrow misleading } & 26\end{array}$

$\begin{array}{ll}\text { Pretty bad } & 24\end{array}$

Small $\quad 6$

Size of Arrow no good 18

Color great -- Arrow very ineffective 28

Long time to find Arrow $\quad 34$

$\begin{array}{lr}\text { Couldn't tell until right up on it } & 16\end{array}$

Arrow blends into nothing 4

$\begin{array}{ll}\text { Not as striking; indicator doesn't show up } & 12\end{array}$

Arrow too small -- have to be right on top to see it 14

$\underline{\text { Sign } 105 \text { RED - } 1.25 \text { - Right - Inconsistent }}$

Arrow too small

More red -- Arrow hard to distinguish $\quad 36$

Can't tell which way to go until approach arrow $\quad 12$

Arrow makes me blind 28

Couldn't see directional signal -- too late $\quad 22$

Arrow too small and on wrong side 14

$\begin{array}{lr}\text { Color good -- Arrow too small, on wrong side } & 16\end{array}$

Little arrow $\quad 20$

Poor direction 6

Arrow no good $\quad 32$

Arrow small

Arrow small; not as light $\quad 10$ 
Arrow too small \& close to letters $\quad 25$

Arrow too small $\quad 15$

Arrow too small color selected very important -- should go w/space around it;

Green stands out better here because of yellow and red in space near it 21

$\begin{array}{ll}\text { Seemed darker } & 27\end{array}$

$\begin{array}{ll}\text { Needs larger caret or more than one } & 17\end{array}$

Arrow is the pits $\quad 29$

Still poor 33

Arrow not big enough $\quad 11$

Harder, poorer arrow $\quad 7$

Arrow hard to see $\quad 19$

$\begin{array}{ll}\text { Little arrows hard to see } & 23\end{array}$

Sign 107 RED - 1.5 - Right - Consistent

Not as clear 13

No tail 33

Terrific EXIT, better arrow $\quad 29$

Prefer bigger arrow $\quad 7$

Not sure what to do 3

Arrow not as clear $\quad 15$

Best to have bigger arrows

Arrow small; doesn't stand out; EXIT ok 25

Arrow not as distinguishable as others 11

$\begin{array}{ll}\text { Too small } & 19\end{array}$

Bright -- not quite as effective $\quad 27$

$\begin{array}{ll}\text { Needs larger caret } & 17\end{array}$

$\begin{array}{ll}\text { Don't read red very well } & 21\end{array}$

Sign 108 GREEN - 1.5 - Left - Inconsistent

Arrow has to be much larger -- position of Arrow counter-intuitive 16 $\begin{array}{ll}\text { Green better than red } & 28\end{array}$

$\begin{array}{ll}\text { Not that visible; green not striking } & 12\end{array}$

Like green arrow; easily seen $\quad 36$

Arrow too small $\quad 32$

$\begin{array}{ll}\text { Arrow too tiny } & 10\end{array}$

$\begin{array}{lr}\text { Arrow on right should not point left } & 6\end{array}$

$\begin{array}{lr}\text { Confused } & 24\end{array}$

Arrow too small; not visible enough $r$

Confusing $\quad 35$

Arrow no good 20 
Sign 108 GREEN - 1.5 - Left - Inconsistent (continued)

Poor contrast -- Arrow on right pointing left causes big problems - in wrong place 34

$\begin{array}{ll}\text { Arrow wrong side } & 14\end{array}$

Other side

Sign 109 RED - 1.75 - Right - Consistent

Arrow pointing left, but on right 28

$\begin{array}{lr}\text { Color, size good } & 6\end{array}$

Arrow easier to distinguish $\quad 36$

Black more visible than red $\quad 26$

Green stands out better, not classically connected with emergency 16

$\begin{array}{ll}\text { Directional no good -- on wrong end -- inconsistent } & 18\end{array}$

Arrow clear $\quad 34$

Opposite side - left should be on left 24

$\begin{array}{ll}\text { Arrow on wrong side } & 20\end{array}$

$\begin{array}{ll}\text { Arrow on wrong side } & 14\end{array}$

Confusing -- because on wrong side $\quad 8$

Would go to sign and take a left at corridor $\quad 12$

Confused by arrow 2

Sign 110 GREEN - 1.75 - Right - Consistent

Arrow is consistent with direction of travel 11

$\begin{array}{ll}\text { Bright } & 27\end{array}$

Green may be better 9

Likes green 3

Green better than red -- bigger arrow better 31

$\begin{array}{ll}\text { Has gotten used to carets } & 19\end{array}$

Real clear; different than red $\quad 7$

Size of arrow -- too small, hard to read in a panic 15

$\begin{array}{ll}\text { Green on arrow more difficult } & 17\end{array}$

$\begin{array}{lr}\text { Big enough to see } & 13\end{array}$

Arrow could be bigger 5

Dull, couldn't see arrow $\quad 25$

Sign 111 RED - 2.0 - Left - Inconsistent

Liked green arrow marker too small 31

Arrow not as good as other $\quad 29$

Be clearer 3

$\begin{array}{lr}\text { Arrow not distinguishable at rating point } & 11\end{array}$

$\begin{array}{ll}\text { Used to red, pay more attention } & 25\end{array}$ 
$\underline{\text { Sign } 111 \text { RED - } 2.0 \text { - Left - Inconsistent (continued) }}$

$\begin{array}{ll}\text { Prompt sign is not a description of proper arrow } & 19\end{array}$

Arrow marginal $\quad 15$

$\begin{array}{ll}\text { Not as big as others } & 13\end{array}$

Easier to read -- caret bigger or doubled 17

$\begin{array}{ll}\text { Like color -- Arrow a bit small } & 27\end{array}$

Sign 112 GREEN - 2.0 - Right - Inconsistent

$\begin{array}{ll}\text { Color better -- Arrow on wrong side } & 20\end{array}$

$\begin{array}{lr}\text { Arrow larger but on wrong side } & 16\end{array}$

Good sign -- arrow in wrong place -- confusing $r$

$\begin{array}{ll}\text { Arrows too small } & 32\end{array}$

$\begin{array}{ll}\text { Arrow needs to be on same side as direction } & 10\end{array}$

Less contrast, color poor. Left side seems harder to see. 34

$\begin{array}{ll}\text { Carets bigger } & 18\end{array}$

Easy to visualize -- good color 14

$\begin{array}{lr}\text { Color good -- arrow on wrong side } & 6\end{array}$

Like green color $\quad 36$

Arrow so small compared w/EXIT $\quad 26$

$\begin{array}{ll}\text { Green may be brighter } & 12\end{array}$

Arrow in wrong place $\quad 35$

$\underline{\text { Sign } 113 \text { RED - } 2.25 \text { - Right - Consistent }}$

Red not as easy as other two colors $\quad 36$

$\begin{array}{ll}\text { Red; can see arrow well } & 12\end{array}$

Arrow bigger, consistent color better 34

Like larger Arrow, color contrast could be greater 16

$\begin{array}{lr}\text { Arrow bigger } & 10 \\ & 18\end{array}$

$\begin{array}{lr}\text { Caret bigger } & 18\end{array}$

Red good; Arrow bold 22

Arrow bigger; even better if black $\quad 26$

Sign 114 GREEN - 2.25 - Left - Inconsistent

$\begin{array}{lr}\text { Could see it -- would have preferred red } & 19\end{array}$

$\begin{array}{ll}\text { Brighter, clear } & 21\end{array}$

Prefer arrow on other side $\quad 7$

$\begin{array}{lr}\text { Not right color, but visible } & 15\end{array}$

Arrow not what people are used to seeing $\quad 11$

Real good 25

Arrow should be on same side as you're going to -- need Arrows that look like arrows 17 
Sign 114 GREEN - 2.25 - Left - Inconsistent (continued)

Beautiful -- one of best 29

Wants bigger arrows 5

Doesn't know if arrow should be on side of direction indicated 9

Wants tail on arrow 33

Sign 115 RED - 2.75 - Right - Inconsistent

Arrow should be on side in which you turn $\quad 23$

Arrow too close to letters 25

On right -- telling you to go left 11

$\begin{array}{ll}\text { Nice \& bright -- larger arrow } & 27\end{array}$

$\begin{array}{ll}\text { Because of size of arrow } & 19\end{array}$

$\begin{array}{lr}\text { More visible } & 15\end{array}$

Good one for reading 13

Jumps out at you to turn the wrong way 29

$\begin{array}{ll}\text { Green best } & 21\end{array}$

$\begin{array}{ll}\text { Legible, easy to read, know direction } & 17\end{array}$

Good size arrow; contrast is not as good as with green 5

$\begin{array}{ll}\text { On opposite side -- arrow on wrong side } & 7\end{array}$

Sign 116 GREEN - 2.75 - Left Consistent

$\begin{array}{ll}\text { Best of all so far } & 26\end{array}$

$\begin{array}{ll}\text { Likes bigger arrow better } & 10\end{array}$

$\begin{array}{ll}\text { Very effective, prefer red } & 16\end{array}$

Read very easily $\quad 36$

$\begin{array}{ll}\text { See arrow; color better, but not better than red } & 20\end{array}$

Better -- bigger can see earlier 30

Don't like green signs - would be "7" if red 18

Would prefer different arrow; a bit bigger 6

$\begin{array}{ll}\text { Good, best so far } & 28\end{array}$

Size, color, stands out $\quad 12$

\section{General Comments made by the Observers}

- Prefers Red signs

- Arrow should be consistent w/direction of travel

- Need arrow where decision needs to be made

- Sign should give information before you're right up on it -- e.g., hazardous material -would like directional information -- give full information at starting point. 


\section{Comments Continued}

- Size of arrow is the big thing in seeing the sign. As soon as someone hits a corridor, they should know which way to go, especially in a fire.

- Had problems with size of Arrows; thinks that when you see EXIT, you expect to know the direction at same time. Prefers to know both; makes him more comfortable. You may not need to know it all the time, but you may really need it in a fire.

- Direction is important. The larger arrow, the better. It should be consistent with direction of travel.

- May be good to have smaller Arrows -- follow sign in emergency but 0.75 -in. too small, perhaps need several arrows -- still would like to see arrow at same time as exit, more likely to see under adverse conditions. May need to use a number of arrows. Arrow should be consistent with direction of travel.

- Instead of caret -- prefer tail to arrow -- prefer consistency w/direction of travel -like arrow to be as big as possible.

- In emergency situation you shouldn't have to worry about where arrow is -- something more solid looking than current arrow -- need bold arrow.

- Red catches eye better; size of arrow should be larger

- Don't like black ones; Arrow consistent w/direction of travel -- red stands out better.

- See dot before arrow; see red better than green or black.

- Red seems brighter; more grabbing than green or grey -- green w/big arrow good. (Subject was slightly color defective)

- Good to have Arrow on side that it's pointing to and be bigger.

- Darker better; Arrow must be bigger, wider, heavier \& sharper

- Side arrow is on is confusing unless consistent; color important; size important.

- Green catches attention because unfamiliar and stands out -- Arrows need to be bigger.

- Fire service experienced. Wants tails on arrow -- tail on E helps. Wants arrow under or above EXIT word, not at end.

- Low Vision subject (20-400 right eye; finger count left eye). Red better than green; bigger Arrows better; consistency of direction of travel important.

- Subject had slight color deficiency; Wants arrow to be same size as letters; put arrow in direction consistent w/direction of travel -- make Arrow larger -- want bigger arrows in black perhaps.

- Likes green and grey better than red. 


\begin{tabular}{|c|c|c|}
\hline \multirow[t]{4}{*}{$\begin{array}{l}\text { NIST-114A } \\
\text { (REV. 3-90) }\end{array}$} & \multirow{4}{*}{$\begin{array}{l}\text { U.S. DEPARTMENT OF COMMERCE } \\
\text { NATIONAL INSTITUTE OF STANDARDS AND TECHNOLOGY } \\
\text { BIBLIOGRAPHIC DATA SHEET }\end{array}$} & $\begin{array}{l}\text { 1. PUBUCATIOH OR REPORT NUMBER } \\
\text { NISTIR } 4532\end{array}$ \\
\hline & & 2. PERFORMINQ ORGAMIZATION REPORT NUMBER \\
\hline & & 3. PUBLCATION DATE \\
\hline & & MARCH 1991 \\
\hline
\end{tabular}

4. TITLE AND SUBTITLE

Visibility of Exit Directional Indicators

5. AUTHOA(S)

Belinda I. Collins, Peter Goodin

6. PERFORMING ORGANIZATION (IF JOINT OR OTHER THAN IST, SEE INSTRUCTIONS) U.S. DEPARTMENT OF COMMERCE

MATIONAL INSTITUTE OF STANDARDS AND TECHNOLOGY

GAITHERSBURG, MO 20899

7. CONTRACT/GRANT NUMBER

8. TYPE OF REPORT AND PERIOD COVERED

9. SPONSORING ORGANIZATION MAME AND COMPLETE ADDRESS (STREET, CITY, STATE, ZIP)

National Electrical Manufacturers Association

2101 L Street, NW

Suite 300

Washington, DC 20037

10. SUPPLEMENTARY NOTES

11. ABSTRACT (A 200-WORD OR LESS FACTUAL SUMMARY OF MOST SIONIFICANT INFORMATION. IF DOCUMENT INCLUDES A SIQNIFICANT BIBLOGRAPHY OR UTERATURE SURVEY, MENTION IT HERE.)

A three-phase experiment assessed the effectiveness of different configurations for exit signs and directional indicators. Two phases involved visibility assessments, while a third phase was a behavioral assessment. In the experiment, sign effectiveness was determined in terms of distance to detection, correct identification, and rated effectiveness, as well as speed through a corridor. The results indicated that a chevron in grey on white with a contrast of about 0.4 to 0.5 (to meet minimum specifications) was identified correctly at the greatest mean distance and received the highest mean ratings of effectiveness, as compared to other directional indicators. The combination of a 2.25-in chevron with a 6-in EXIT sign was identified correctly at a mean distance of about $100 \mathrm{ft}$. Use of color, either red or green, increased this distance by about 15 to $20 \mathrm{ft}$. Reducing width to height ratio reduced identification distance by about 35-40 ft for chevrons of comparable height, although chevrons of 2.6 to 3.75 -in. in height, with a width to height ratio of 0.29 to 0.43 , were identified correctly at about $100 \mathrm{ft}$. These data suggest that chevron width could be reduced if height were increased above 2.6-in, and still maintain adequate visibility at $100 \mathrm{ft}$. However, visibility is best predicted by total chevron area, with chevrons with larger total areas seen at greater distances. Analysis of the movement data from the behavioral phase indicated that chevrons of 2.25 -in provided adequate visibility at about $100 \mathrm{ft}$ but that speed of movement is not a sensitive indicator for sign visibility. Finally, the data from all three phases indicate the importance of chevron size and configuration as well as sign color and contrast in determining visibility.

12. KEY WORDS (6 TO 12 ENTRIES; ALPHABETICAL ORDER; CAPITAUZE ONLY PROPER NAMES; AND SEPARATE KEY WORDS BY SEMICOLONS)

arrows; chevrons; color; contrast; directional indicators; exit; egress; emergency

lighting; sign; visibility

13. AVAILABIUTY

UNLMMITED

FOR OFFICIAL DISTRIBUTION. DO NOT RELEASE TO NATIONAL TECHNICAL INFORMATION SERVCE (NTIS).

ORDER FROM SUPERINTENDENT OF DOCUMENTS, U.S. GOVERNMENT PRINTING OFFICE, WASHINGTON, DC 20402.

ORDER FROM NATIONAL. TECHNICAL INFORMATION SERVICE (NTIS), SPRINGFIELD, VA 22161.

14. NUMBER OF PRINTED PAGES

43

15. PRICE

A03 

